Sharif University of Technology
Scientia Iranica
SCIENTIA
I RAN I CA
http://scientiairanica.sharif.edu

\title{
Loading frequency effect on dynamic properties of mixed sandy soils
}

\author{
A. Aghaei Araei ${ }^{a, *}$ and A. Ghodrati ${ }^{b}$ \\ a. Road, Housing and Urban Development Research Center (BHRC), Geotechnical Department, Tehran, P.O. Box 13145-1696, Iran. \\ b. Road, Housing and Urban Development Research Center (BHRC), Institute of Building and Housing, Tehran, Iran. \\ Received 24 September 2016; received in revised form 9 January 2017; accepted 11 March 2017
}

\author{
KEYWORDS \\ Frequency; \\ Mixed sandy soils; \\ Triaxial; \\ Shear modulus; \\ Damping ratio.
}

\begin{abstract}
Most previous studies have focused on pure (clean) sands, silts, and clays; no concrete and diligent effort has been made to understand dynamic behaviors of natural sandy soils. The purpose of this paper is to evaluate the effect of loading frequency, as one of the most important factors, on the dynamic properties, especially stiffness and damping characteristics of natural sandy soils mixed with silt and gravel. For this purpose, 40 dynamic triaxial tests were carried out on the cylindrical samples prepared from three mixed sandy materials. Cyclic tests were performed using large triaxial apparatus under different confinement conditions, waveforms, and loading frequencies. Results showed that shear modulus and damping ratio were dependent on confining pressure and loading frequency. Shear modulus and damping ratio increased as loading frequency increased. Moreover, the shear modulus increased as confining pressure increased; however, damping ratio decreased. However, the effect of triangular, sinusoidal, and rectangular waveforms on the dynamic behavior was negligible. In the studied ranges of strains, the effects of the number of cyclic loadings and excess pore water pressure over $G / G_{\max }$ and $D$ were negligible. There are considerable differences between the obtained results of the tested soils and literature results, even for almost the same loading frequencies.
\end{abstract}

(C) 2018 Sharif University of Technology. All rights reserved.

\section{Introduction}

Sand is rarely found clean and pure in natural deposits and is usually found in composition of clay, silt, and gravel. Most previous researches have concentrated on uniform clean sands, or sands with little fines. Published results are inconclusive in clarifying the effect of added fines on sands. It has been reported that, due to particle size disparity and the availability of pores larger than the added particles, some fine particles can

\footnotetext{
*. Corresponding author. Tel.: +98 2188255942 ; Fax: +9821 88255942

E-mail addresses: aghaeiaraei@bhrc.ac.ir (A. Aghaei Araei); a.ghodrati@bhrc.ac.ir (A. Ghodrati)
}

doi: $10.24200 /$ sci. 2017.4209 occupy a part of the void space and, eventually, play little or no part in the response of the mixtures $[1,2]$. The gravel content also plays an important role in dynamic behavior of sand mixture [3,4]. However, it should be recognized that the existence of fractions of clay, silt, and gravel could affect sand's behavior remarkably. On the other hand, an increase in demand of the alluvial deposits and response spectra in cities' microzonation projects highlights the importance of studying the dynamic behavior of shallower layers. The exact information and knowledge of strain-dependent shear modulus $(G-\gamma)$, damping ratio $(D-\gamma)$, and low strain shear modulus of the studied materials is necessary in such analyses.

Almost none of $G-\gamma$ and $D-\gamma$ relationships was available for soils containing large particles up until when Seed et al. [5] published results of large-scale 
(diameter about $300 \mathrm{~mm}$ ) cyclic triaxial tests. Over the three past decades, results have become available to many investigators. These studies are limited to the tests performed under loading frequency less than $0.2 \mathrm{~Hz}$. More results have become available in recent years to other researchers, yet most of them were carried out under low frequency loading (less than $0.2 \mathrm{~Hz})$.

Previous tests results on soils were obtained under the following conditions: undisturbed and reconstituted specimen, loading frequency from 0.01 to $0.2 \mathrm{~Hz}$, confining pressure from 29 to $490 \mathrm{kPa}$, sample density from 27 to 95 percent, applied cycles number from 3 to 12 cycles, fine contents from 0 to 9 percent, and maximum grain size from 10 to $150 \mathrm{~mm}$.

Strong motion records from the recent earthquakes, including 1994 Northridge, 1995 Kobe, 1999 Chi-Chi, and 2003 Bam events, have shown the importance of local site conditions in the propagated ground motions [6]. One-dimensional site response analysis is widely performed to account for local site effects during an earthquake [7-9]. The dynamic soil properties have been assumed to be frequency independent in most of these approaches.

Laboratory test results, including non-resonance method in Resonant-Column (RC) test, undrained cyclic torsional simple shear tests using hollow cylindrical torsional shear apparatus, cyclic triaxial, bender element, model tests including shake table, and centrifuge as well as in-situ soil-specific nonlinear dynamic properties back-calculated from vertical array records during earthquake, show that shear modulus and damping ratio are dependent on the frequency of loading [6]. Owing to the limited available data for different soils at low strain, Park and Hashash assumed that only the small strain shear modulus and damping ratio are frequency dependent [9]. However, the dependency of soil dynamic properties on frequency even at low strain is not modelled clearly.

The linear theory of viscoelasticity can describe the low strain mechanical behavior of soils exposed to dynamic excitation accurately. This theory is able to accurately simulate, from a phenomenological point of view, two important features exhibited by soils undergoing harmonic oscillations: their ability to store, and, at the same time, to dissipate strain energy over a finite period of time [10-12]. An important consequence of reformulating the low strain dynamic properties of soils, within the framework of the theory of viscoelasticity, is that the velocity of propagation of body waves, in particular, shear wave (or shear modulus), and the material damping are not two independent parameters [6]. Their functional coupling is a direct consequence of material dispersion, a phenomenon by which, in viscoelastic media, the velocity of propagation of mechanical disturbance has to be frequency dependent in order to satisfy the fundamental principle of causality [6]. As a result of their mutual dependence, shear modulus and damping in soils should be measured simultaneously, even though, in current geotechnical engineering testing practice, these two parameters are determined separately $[10,13]$.

In addition, Khan et al. [14] showed that the dynamic properties of soils exhibiting strong viscoelastic behavior cannot be considered to be frequency independent in the earthquake frequency bandwidth $(<30 \mathrm{~Hz})$ [11], even for low strain level excitations [10] as is (happens to be) the common practice in geotechnical engineering [15].

Results of numerical analysis show that the greater part of earthquake energy is in the frequency range of 1 to $5 \mathrm{~Hz}$ [16]. However, all the cyclic deviator stresses using triaxial tests, in earlier studies, were applied in uniform sinusoidal cycles at frequencies of up to $0.2 \mathrm{~Hz}$ [17]. The low frequency may be selected in order to measure the deformation accurately. ASTM D3999 [18] recommended the frequency variation between 0.1 and $2 \mathrm{~Hz}$. Zhang et al. [19] indicated that there is a significant discrepancy at small strain levels between the recommended $D$ curve and test data for $D_{\text {min }}$ at different loading frequencies of sands and finegrained soils.

Earthquake ground motion simulation with frequency-dependent soil properties, conducted by Meng [11] and Park and Hashash [9], demonstrates that the dynamic properties of soils play an important role in the near surface earthquake ground motion analyses and need to be used in the same way as they were measured. The above-mentioned studies were limited to the fine-grained and pure sands at low shear strains.

A study conducted by Aghaei Araei et al. [20] on gravel materials with fine content ranges from 0 to $49 \%$ under loading frequency range of 0.1 to $1 \mathrm{~Hz}$ shows that damping value at loading frequency of $1 \mathrm{~Hz}$ at low strain is much higher than the corresponding results presented by Seed et al. [5] and Rollins et al. [17].

Maheshwari [21] performed strain controlled undrained cyclic triaxial tests to evaluate shear modulus and damping ratio of the Solani sand. The tests' results showed that the frequency of loading does not have a significant effect on the normalized modulus in the test range of shear strain. However, the damping ratios are affected to some extent by the frequency of loading, as higher damping ratios are observed at higher frequencies [21].

Extensive triaxial testing by Aghaei Araei et al. [22-24] on gravels (e.g., frequency and confining pressure range from 0.1 to $10 \mathrm{~Hz}$ and 100 to 1500 $\mathrm{kPa}$, respectively) revealed that the shear modulus and, especially, the damping ratio behaviors are influenced by the loading frequency. An increase in loading frequency increases shear modulus at low strain; however, 
the effect of frequency decreases as strain increases. The damping ratio increases considerably by increasing the loading frequency. The shear modulus increases remarkably by increasing the confining pressure; however, the damping ratio negligibly changes [22-24]. Ling et al. [25] studied the dynamic shear modulus and damping ratio of compacted sand subjected to freeze-thaw cycle under multi-stage cyclic loading. The results indicated that the dynamic shear modulus increases with the increasing initial water content, temperature, loading frequency, and confining pressure [25].

Therefore, the reassessment of the loading frequency effects over other materials, such as natural sands, silts, and clays, via laboratory test is necessary not only at low strain, but also at medium and high strains via simultaneous measurement of shear modulus and damping ratio. By considering limitations of available suitable laboratory test results and available facilities, such as large-scale triaxial apparatus, in the Geotechnical laboratory at BHRC, it is useful to carry out an investigation to determine their behavior in order to have safe and economic designs and constructions.

Despite many experimental efforts made on finegrained and sandy soils, there is only limited information about the behavior of mixed natural sandy soils under different loading frequencies. This research focuses on the effects of different parameters, especially loading frequency, waveforms, and confining pressure on dynamic behavior (i.e., shear modulus and damping ratio) of compacted natural sandy materials using large-scale triaxial equipment. Moreover, these results were compared to behavior curves available in the literature for similar soils in site response analyses, namely $[7,26,27]$.

\section{Material properties}

In this study, the tested samples (three soils types) were obtained from the drilling boreholes form three cities in Iran. Characteristics of the used soils were unified and similar in the whole log profiles. Table 1 presents the main characteristics of tested materials, including soil type in Unified Soil Classification System, size distribution, specific gravity, dry density and optimum water content, minimum void ratio, plasticity index and $P / S$ wave velocity values. SM, SW, and SC were coarse grains (sand) and obtained from three boreholes related to Sorkheh, Semnan, and Pardis cities. The gradation curves of the materials for triaxial testing were obtained with maximum particle sizes of $38 \mathrm{~mm}$ (about 1/6 diameter of large-scale triaxial specimen, which is $200 \mathrm{~mm}$ ). SM, SW, and SC materials consist of 25,2 , and $16 \%$ fine grains, and passing percentage from sieve no. $4(4.75 \mathrm{~mm})$ is equal to 65,57 , and $86 \%$, respectively. The maximum dry densities and optimum water contents were evaluated for samples according to the standard proctor (ASTM D698 [28]). Specific gravity $\left(G_{s}\right)$ ranges from 2.39 to 2.69 , and minimum void ratio $\left(e_{0}\right)$ varies from 0.133 to 0.363 for the tested materials.

\section{Dynamic testing programs}

Several specimens of different materials were prepared and tested under different confining pressure conditions. The range of confining pressures in testing was chosen with respect to the experienced stresses' levels in soil profile (100 kPa for shallow layers, $200 \mathrm{kPa}$ for intermediate layers and $500 \mathrm{kPa}$ for deep layers). These tests were conducted on specimens on a large scale with $200 \mathrm{~mm}$ diameter and $400 \mathrm{~mm}$ height under different loading frequencies using the large-scale triaxial equipment. In all tests, a non-contact high sensitivity deformation transducer and two load cells were used. One of them was located outside the test cell and the other (the submersible type load cell) inside the cell. Deformation non-contact strain sensors were located on the both sides of the top plate in order to determine the average strain and eliminate the rotational component. These techniques exclude friction in the loading piston from measurements. All dynamic cyclic tests were performed according to ASTM D3999 [18] under effective confining pressures of 100,200 , and $500 \mathrm{kPa}$ at frequencies of $0.5,1,2,5$, and $10 \mathrm{~Hz}$, respectively. Effects of triangular, sinusoidal, and rectangular waveforms were also investigated over dynamic properties at different loading frequencies. The sinusoidal waveform was the main one in all cyclic triaxial tests; however, triangular and rectangular loading waveforms were applied at the three shear strain levels (low, medium, and large strains). About 40 tests were performed under different conditions on cylindrical specimens.

\section{Testing procedure}

The weight proportion of various grain sizes required to achieve the material grain size distributions was determined by the weight of each specimen. The specimens were prepared according to maximum dry density through adding optimum moisture content. In this study, specimens were prepared with their natural gradation and density due to representing the initial state of soils. The soil layers in the nature are neither completely dry nor saturated, but a state between these conditions. On the other hand, tested materials were obtained from the boreholes of the aged deposits. According to geological analysis of the studied regions, these deposits experienced relatively strong earthquakes and almost reached their maximum 
Table 1. The characteristics of sandy materials used in cyclic triaxial tests.

\begin{tabular}{|c|c|c|c|c|c|c|}
\hline City (borehole no.) & \multicolumn{2}{|c|}{ Sorkheh (BH8) } & \multicolumn{2}{|c|}{ Semnan (BH32) } & \multicolumn{2}{|c|}{ Pardis (BH8) } \\
\hline Soil type in unified soil classification system & \multicolumn{2}{|c|}{ SM } & \multicolumn{2}{|c|}{ SW } & \multicolumn{2}{|c|}{$\mathrm{SC}$} \\
\hline Maximum particle size (mm) & \multicolumn{6}{|c|}{38} \\
\hline$D_{(10)}, D_{(30)}, D_{(50)}(\mathrm{mm})$ & \multicolumn{2}{|c|}{$(0.02,0.16,1.5)$} & \multicolumn{2}{|c|}{$(0.39,1.7,3.7)$} & \multicolumn{2}{|c|}{$(0.03,0.21,0.6)$} \\
\hline Passing \#200 (\%) & \multicolumn{2}{|c|}{25} & \multicolumn{2}{|c|}{2} & \multicolumn{2}{|c|}{16} \\
\hline Gs (bulk specific gravity-oven dry) & \multicolumn{2}{|c|}{2.61} & \multicolumn{2}{|c|}{2.65} & \multicolumn{2}{|c|}{2.36} \\
\hline$\gamma_{d(\max )}\left(\mathrm{kN} / \mathrm{m}^{3}\right)$ & \multicolumn{2}{|c|}{20.5} & \multicolumn{2}{|c|}{23.3} & \multicolumn{2}{|c|}{17.2} \\
\hline$\omega_{\text {opt }}(\%)$ & \multicolumn{2}{|c|}{9.3} & \multicolumn{2}{|c|}{6.1} & \multicolumn{2}{|c|}{17} \\
\hline$e_{0}$ & \multicolumn{2}{|c|}{0.249} & \multicolumn{2}{|c|}{0.133} & \multicolumn{2}{|c|}{0.363} \\
\hline PI $(\%)$ & & & & & & \\
\hline Depth $(\mathrm{m})$ & $V_{s}(\mathrm{~m} / \mathrm{s})$ & $V_{p}(\mathrm{~m} / \mathrm{s})$ & $V_{s}(\mathrm{~m} / \mathrm{s})$ & $V_{p}(\mathrm{~m} / \mathrm{s})$ & $V_{s}(\mathrm{~m} / \mathrm{s})$ & $V_{p}(\mathrm{~m} / \mathrm{s})$ \\
\hline 1 & 196 & 410 & 212 & 440 & 184 & 451 \\
\hline 2 & 296 & 582 & 260 & 530 & 184 & 420 \\
\hline 3 & 370 & 722 & 292 & 574 & 308 & 602 \\
\hline 4 & 443 & 836 & 334 & 630 & 463 & 880 \\
\hline 5 & 481 & 899 & 341 & 641 & 456 & 817 \\
\hline 6 & 514 & 934 & 432 & 812 & 559 & 1016 \\
\hline 7 & 437 & 804 & 564 & 1040 & 723 & 1165 \\
\hline 8 & 508 & 966 & 576 & 1061 & 746 & 1347 \\
\hline 9 & 570 & 1078 & 660 & 1201 & 733 & 1206 \\
\hline 10 & 543 & 980 & 646 & 1213 & 691 & 1216 \\
\hline 11 & 631 & 1153 & 775 & 1491 & 651 & 1091 \\
\hline 12 & 634 & 1158 & 780 & 1501 & 884 & 1625 \\
\hline 13 & 598 & 1098 & 784 & 1403 & 755 & 1405 \\
\hline 14 & 658 & 1235 & 618 & 1100 & 979 & 1639 \\
\hline 15 & 639 & 1166 & 682 & 1237 & 760 & 1412 \\
\hline 16 & 584 & 1046 & 452 & 830 & 897 & 1647 \\
\hline 17 & 498 & 905 & 661 & 1240 & 825 & 1417 \\
\hline 18 & 524 & 995 & 553 & 995 & 900 & 1652 \\
\hline 19 & 641 & 1243 & 763 & 1418 & 902 & 1803 \\
\hline 20 & 736 & 1419 & 991 & 1802 & 992 & 1983 \\
\hline 21 & 737 & 1421 & 1101 & 1982 & 1102 & 2203 \\
\hline 22 & 687 & 1327 & 946 & 1806 & 1103 & 1987 \\
\hline 23 & 623 & 1173 & 1045 & 1986 & 905 & 1809 \\
\hline 24 & 796 & 1423 & 1104 & 1988 & 1105 & 2209 \\
\hline 25 & 866 & 1532 & 1169 & 2115 & 804 & 1510 \\
\hline 26 & 797 & 1424 & 1170 & 2073 & 996 & 1844 \\
\hline 27 & 874 & 1533 & & & 1243 & 2211 \\
\hline 28 & 940 & 1661 & & & 1214 & 2212 \\
\hline 29 & & & & & & \\
\hline 30 & & & & & & \\
\hline
\end{tabular}

density. The results have been verified using standard proctor (ASTM D698 [28]). Therefore, in order to simulate the real conditions of deposits and implement the same procedure, the specimens were been prepared in their maximum dry density by adding optimum moisture content. The sample materials were divided into four parts. Each layer was compacted in a split mold by means of a compactor with the frequency of 60 cycles/sec. The loading was applied under initial isotropic condition (consolidation pressures). Due to extra cost, time required, and simplicity in using only one specimen, the cyclic shear tests were typically performed using a staged approach. At first, a limited number of cycles (i.e., 40 cycles), with the given waveforms and loading frequencies, were applied at a very small strain level. Test results for cycles 1 to 40 were recorded by the data acquisition. Due to preparing the samples at the optimum moisture content, the 
water fills almost all empty space between the grains, theoretically (i.e., zero void ratio). Therefore, it can be expected that pore water pressure be produced during cyclic loading at medium and high strain levels. However, its value is very low, compared to the saturated samples (less than $10 \%$ ). Generally, according to ASTM D3999 [18], the specimen drainage valves open after each stage of cyclic loading to re-establish the effective consolidation stress or maintain the existing excess pore water pressure before moving on to the next higher cyclic load or deformation level. However, excess pore water pressure is generated during the cyclic loading (ASTM D3999 [18]); however, all of the calculations were performed based on the initial effective stress at the studied strain levels. The excess pore water pressure produced during this cyclic loading was dissipated by opening the drainage valve so that the original effective stresses could be retrieved. This procedure was then repeated for higher strain levels (about twice the initial amplitude) until the maximum shear strain level was attained. When the pore pressure was released due to opening the drainage valve, the volume of the specimen may decrease; thus, the sample became a little denser. The change in volume depends on the number of strain cycles applied, sample type, and axial strain amplitude. It was found that the amount of change in density was negligible for small strain amplitudes and was still very small even for strain amplitudes of up to $0.1 \%$ if the number of strain cycles was limited [5]. Therefore, it is believed that the re-use of samples for higher strain amplitudes still gives reasonably good results if the number of strain cycles applied is limited [5]. Axial loads, vertical displacements, volume changes, and pore pressures were measured at periodic intervals of $0.04,0.02,0.01$, 0.004 , and 0.002 seconds, respectively, for the applied load with frequencies of $0.5,1,2,5$, and $10 \mathrm{~Hz}$ in undrained conditions. Table 2 summarizes the characteristics of triaxial testing program including confining pressure, loading frequency, number of loading cycles and samples prepared.

\section{Cyclic test results}

Tests results, including shear modulus and damping ratio versus shear strains, have been calculated based on the stress-strain hysteresis loop (see Figure 1) for

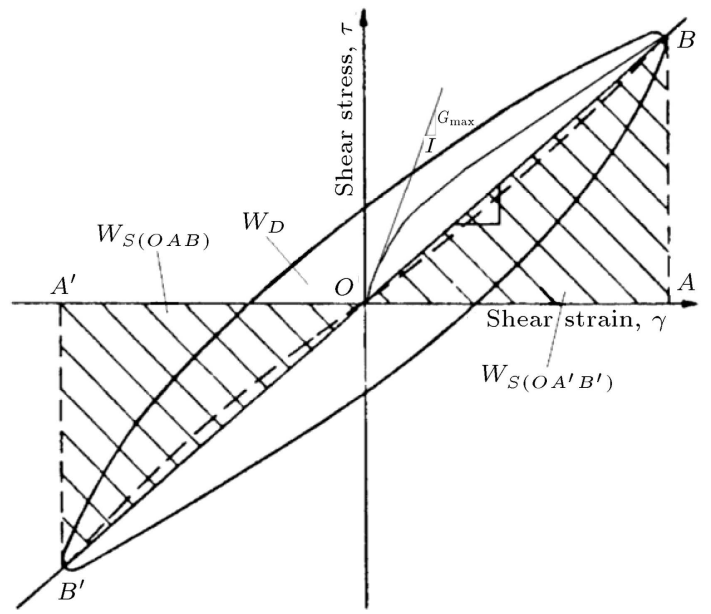

Figure 1. Calculation of shear modulus and damping ratio based on the stress-strain hysteresis loop.

the 1st to 40th cycles, according to ASTM D3999 [18]. The following equations were used to calculate shear strain and shear modulus:

$$
\begin{aligned}
& E=\frac{\tau}{2 \varepsilon_{a}}, \\
& \gamma=(1+v) \varepsilon_{1}, \\
& G=\frac{E}{2(1+v)},
\end{aligned}
$$

where $E$ is Young modulus, $\tau$ is shear stress, $\varepsilon_{1}$ is axial strain, $\gamma$ is shear strain, and $v$ is Poisson's ratio. Poisson's ratio, $v$, is measured based on the following equation for specimens in an unsaturated condition:

$$
v=\frac{\left(V_{p} / V_{s}\right)^{2}-2}{2\left(V_{p} / V_{s}\right)^{2}-1},
$$

where $V_{p}$ and $V_{s}$ represent the velocities of $P$ and $S$ waves in the studied boreholes profiles. Poisson's ratio, $v$, was calculated with respect to various depths of soil profiles of the tested materials; then, their average values were considered in calculations. The Poisson's ratio was equal to 0.29 for the three materials. For example, the specimen (e.g., SM) tested under confining pressure of $100 \mathrm{kPa}$ was prepared from the depths of 6 to $10 \mathrm{~m}$ of the soil profile. The average value of Poisson's ratio at these depths is equal to 0.29. The average value of Poisson's ratio for SW and SC

Table 2. The characteristics of triaxial testing program performed on mixed sandy soils according to ASTM D3999 [17].

\begin{tabular}{ccccc}
\hline Material symbol & $\boldsymbol{\sigma}_{\mathbf{3}}^{\prime} \mathbf{( k P a )}$ & Number of cycles & Frequency of loading $(\mathbf{H z})$ & Total tests no. \\
\hline SM & $100,200,500$ & 40 & $0.5,1,2,5,10$ & 15 \\
SW & $100,200,500$ & 40 & $1,2^{*}, 5,10$ & 10 \\
SC & $100,200,500$ & 40 & $0.5,1,2,5,10$ & 15 \\
\hline
\end{tabular}

* Only at confining pressure of $100 \mathrm{kPa}$ 
specimens tested under confining pressure of $100 \mathrm{kPa}$ is also equal to 0.29 .

The hysteresis damping ratio (the word hysteresis means "lag" or "delay" and comes from ancient Greek) or the time-lag between a driven cyclic stress and driven strain is calculated as follows:

$$
D=\frac{W_{D}}{2 \pi\left(W_{S(0 A B)}+W_{S\left(0 A^{\prime} B^{\prime}\right)}\right)} \times 100(\%),
$$

where $W_{D}$ is the energy dissipated in one cycle of loading, and $W_{s}$ is the maximum strain energy stored during the cycle.

\subsection{Frequency-dependent shear modulus}

Results of $G$ versus shear strain at confining pressures of 100,200 , and $500 \mathrm{kPa}$ and loading frequencies of $0.5,1,2,5$, and $10 \mathrm{~Hz}$ for SM, SW, and SC materials are presented in Figure 2. The measured strain range is about 0.0001 to up $1 \%$. According to Figure 2, at low strain amplitudes, the shear modulus is nearly constant and at its highest value, $G_{\max }$; however, it decreases as the strain amplitude increases. The effect of loading frequency on shear modulus at all strain levels is remarkable. Generally, the shear modulus increases as loading frequency increases, especially at the low strains. However, for some materials, as shear strain increases, the effect of loading frequency on the values of $G$ decreases; the rate of increase in $G$ at low strains is higher than the corresponding value at a higher strain. The amplitude of strain values decreases in higher loading frequencies (e.g., $5 \mathrm{~Hz}$ and $10 \mathrm{~Hz}$ ).

Contrary to the observed behavior for gravelly materials [24], the frequency of loading had a significant impact on $G$ at strain levels higher than $0.01 \%$. In general, at low and medium strain levels, an increase in loading frequency causes dispersion in $G-\gamma$ curve and an increase in $G$. The confining pressure has a considerable effect on strain values. As expected, the higher the value of confining pressure is, the lower the amount of shear strain will be. Therefore, system performance in applying shear strains is highly affected by frequency and confining pressure.

\subsection{Frequency-dependent maximum shear modulus}

Many efforts have been made by researchers to develop equations for estimating maximum shear modulus, $G_{\text {max }}$. High sensitive non-contact coiled deformation transducers located on the opposite sides of the top plated are used to measure the average strain and eliminate the rotational component. The maximum range of measurement is $2.5 \mathrm{~mm}$ with accuracy of less than $0.001 \mathrm{~mm}$. In this study, the extrapolation method was employed from $0.0001 \%$ strain to obtain $G_{\max }$ for the material (which is also used in $[5,24]$ ). For this purpose, the following equation has been used to determine $G_{\max }$ :

$$
G_{\max }=A \cdot f(e) \cdot\left(\sigma_{3}^{\prime}\right)^{n}, f(e)=(2.17-e)^{2} /(1+e),
$$

where $A$ and $n$ are the empirical constants, and $e$ is the material void ratio. $G_{\max }$ values of $\mathrm{SM}, \mathrm{SW}$, and SC materials under different confining pressures and loading frequencies are presented in Table 3 . The material void ratio at the end of specimen consolidation is one of the most crucial parameters in $G_{\max }$ estimation using experimental equations (e.g., $[5,29]$. The void ratio at the end of specimen consolidation is determined by measuring the volume change due to drainage after applying the isotropic confining pressure. As presented in Table 3 , the variation of void ratio due to consolidation is negligible because of preparing the specimens at optimum moisture content. $G_{\max }$, $A$, and $n$ values are determined by plotting $G / f(e)$ versus confining pressure in the logarithmic form (the relationship between parameters is assumed to be linear in this method).

According to Table $3, G_{\max } / f(e)$ value increases as confining pressure and loading frequency increase. The rate of shear modulus (due to loading frequency) increases by increasing the confining pressure. The difference of $G_{\max }$ with respect to its values at $1 \mathrm{~Hz}$ (\%) varies from -11.4 to 45.7 , from 8.7 to 41.1 , and from -7.7 to $27.1 \%$ for SM, SW, and SC, respectively. The extent of variations in $G_{\max }$ could not be due to the test errors (testing tools or measuring errors). Constants $A$ and $n$ are also presented in Table 3 . $A$ and $n$ constants range from 22.9 to 76.7 and 0.2585 to 0.6053 , respectively.

Results of $G_{\max }$ under different confining pressures for loading frequencies of $0.5,1,2,5$, and 10 $\mathrm{Hz}$ for SM, SW, and $\mathrm{SC}$ materials are presented in Figure 3. It is observed that SC material is less affected by loading frequency and has the lowest shear modulus value among the tested materials. The confining pressure has also the least effect on the maximum shear modulus of this material. SM material, $G_{\max }$, showed the maximum dependency on loading frequency and confining pressure compared to the three other tested materials. SM material has the highest $G_{\max }$.

\subsection{Frequency-dependent $G / G_{\max }$}

Generally, in practice, shear modulus, $G$, is more applicable than maximum shear stress, $G_{\max }$. Thus, the variations of $G / G_{\max }-\gamma$ for soils under various circumstances have great importance. $G / G_{\max }-\gamma$ curves presented by Seed and Idriss [7] have been used by many researchers and engineers for many years. In addition, the variations of $G / G_{\max }-\gamma$ of sands for different plasticity indices have been presented in EPRI [26]. Furthermore, Kokusho [27] proposed $G / G_{\max }-\gamma$ relationship for non-plastic sands 


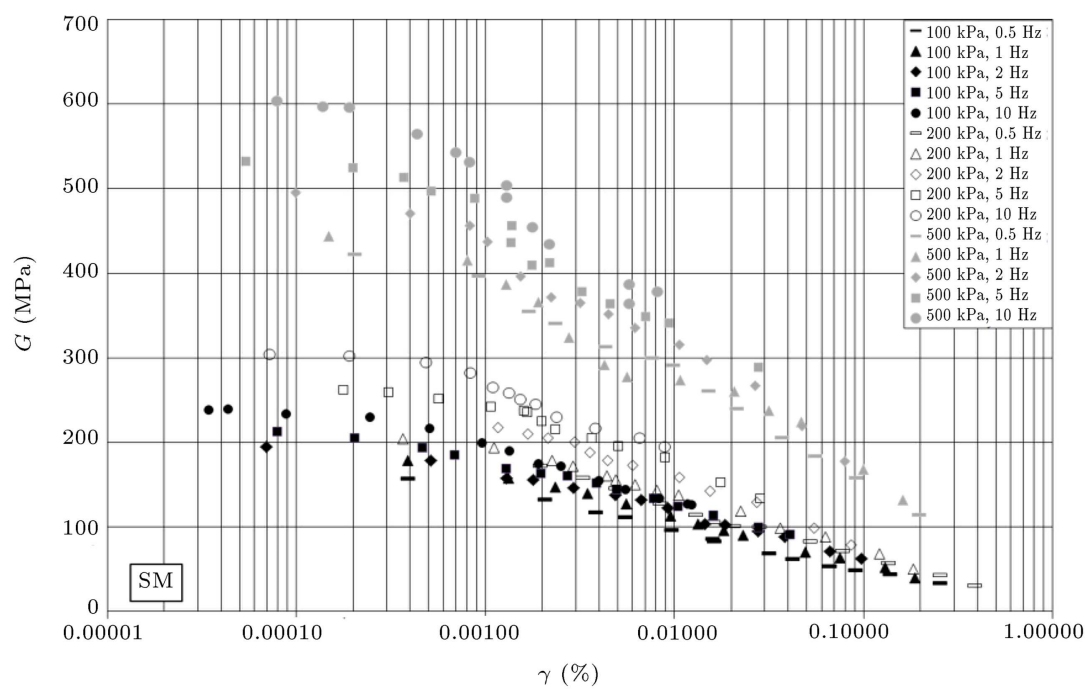

(a)

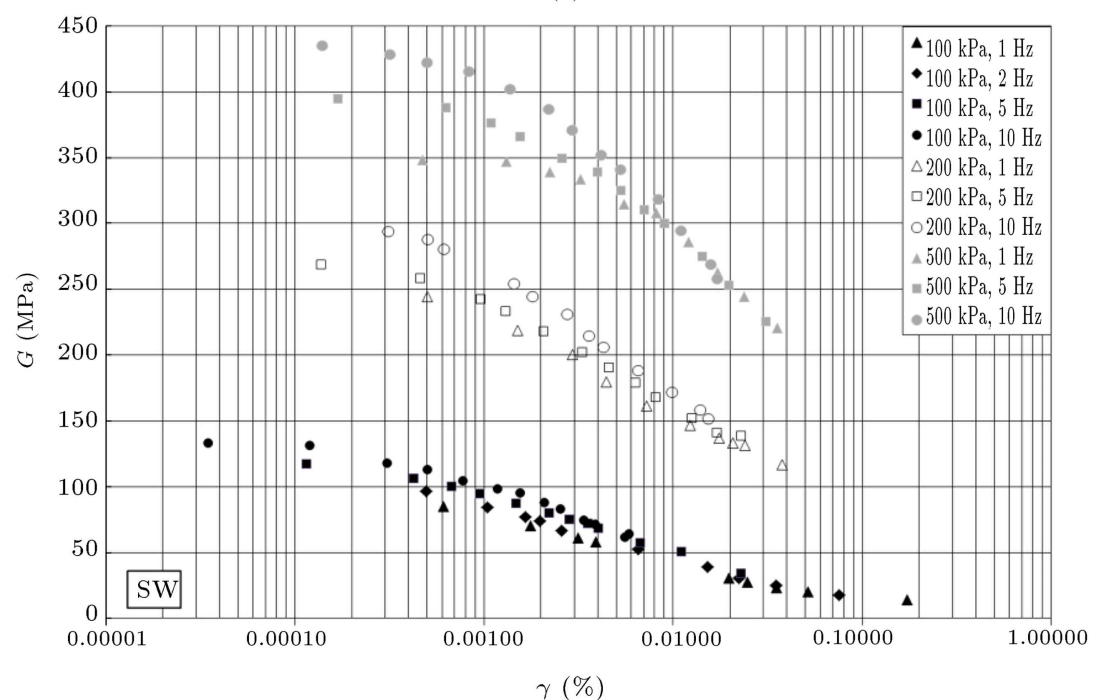

(b)

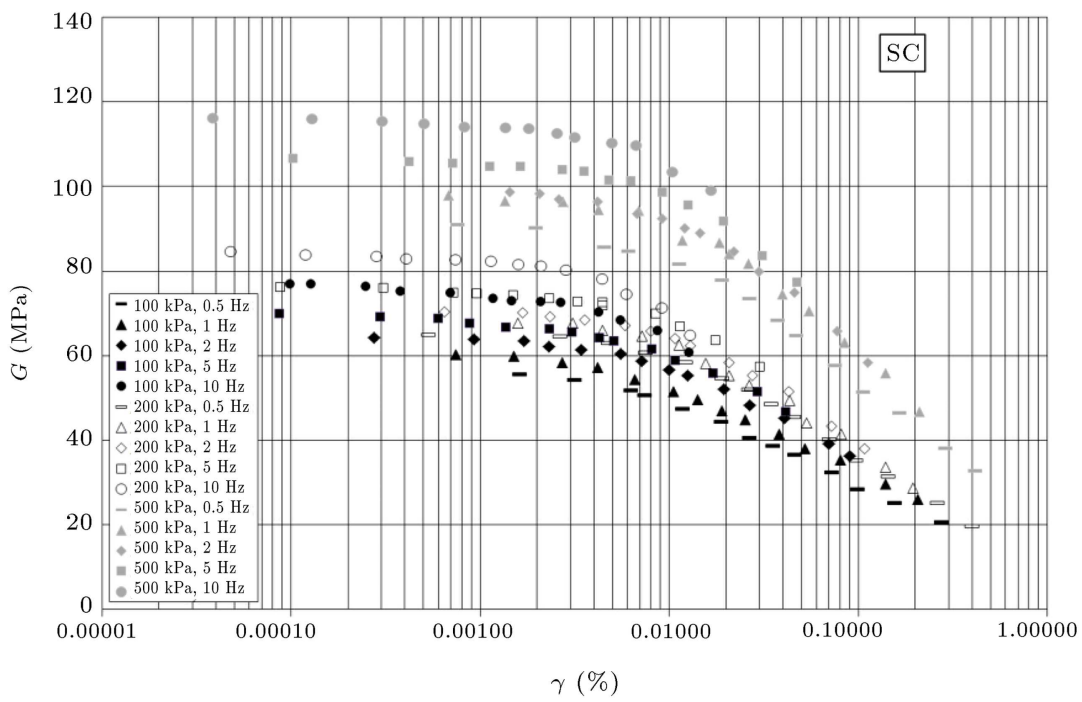

(c)

Figure 2. Results of shear modulus versus shear strain at different confining pressures and loading frequencies: (a) SM, (b) SW and (c) SC. 
Table 3. $G_{\max }$ values for SM, SW, and SW materials under different confining pressures and loading frequencies.

\begin{tabular}{|c|c|c|c|c|c|c|c|c|}
\hline Material & $\begin{array}{c}\sigma_{3}^{\prime} \\
(\mathrm{kPa})\end{array}$ & $\begin{array}{c}\text { Loading } \\
\text { frequency } \\
\quad(\mathrm{Hz})\end{array}$ & $\begin{array}{c}\text { Volume change at } \\
\text { end of consol. } \\
\text { (liter) }\end{array}$ & $f(e)$ & $\boldsymbol{A}$ & $n$ & $\begin{array}{c}\text { Measured } \\
G_{\max } \\
(\mathrm{MPa})\end{array}$ & $\begin{array}{l}\text { Different in } G_{\max } \\
\text { with respect to its } \\
\text { values at } 1 \mathrm{~Hz}(\%)\end{array}$ \\
\hline \multirow{15}{*}{ SM } & \multirow{5}{*}{100} & 0.5 & \multirow{5}{*}{0.002} & \multirow{5}{*}{2.954663} & 51.6 & 0.6053 & 168 & -11.4 \\
\hline & & 1 & & & 57.8 & 0.5621 & 189 & 0.0 \\
\hline & & 2 & & & 62.1 & 0.5887 & 199 & 5.3 \\
\hline & & 5 & & & 68.4 & 0.5851 & 215 & 13.4 \\
\hline & & 10 & & & 76.7 & 0.5823 & 240 & 27.0 \\
\hline & \multirow{5}{*}{200} & 0.5 & \multirow{5}{*}{0.003} & \multirow{5}{*}{2.954663} & 51.6 & 0.6053 & 196 & -6.5 \\
\hline & & 1 & & & 57.8 & 0.5621 & 210 & 0.0 \\
\hline & & 2 & & & 62.1 & 0.5887 & 239 & 13.6 \\
\hline & & 5 & & & 68.4 & 0.5851 & 273 & 29.8 \\
\hline & & 10 & & & 76.7 & 0.5823 & 306 & 45.7 \\
\hline & \multirow{5}{*}{500} & 0.5 & \multirow{5}{*}{0.001} & \multirow{5}{*}{2.954663} & 51.6 & 0.6053 & 434 & -4.8 \\
\hline & & 1 & & & 57.8 & 0.5621 & 456 & 0.0 \\
\hline & & 2 & & & 62.1 & 0.5887 & 504 & 10.5 \\
\hline & & 5 & & & 68.4 & 0.5851 & 543 & 18.9 \\
\hline & & 10 & & & 76.7 & 0.5823 & 605 & 32.6 \\
\hline \multirow{10}{*}{ SW } & \multirow{4}{*}{100} & 1 & \multirow{4}{*}{0.001} & \multirow{4}{*}{4.7089} & 40.4 & 0.3663 & 95 & 0.0 \\
\hline & & 2 & & & - & - & 106 & 11.8 \\
\hline & & 5 & & & 42.4 & 0.4108 & 118 & 23.9 \\
\hline & & 10 & & & 47.8 & 0.3941 & 134 & 41.1 \\
\hline & \multirow{3}{*}{200} & 1 & \multirow{3}{*}{0.002} & \multirow{3}{*}{4.7089} & 40.4 & 0.3663 & 253 & 0.0 \\
\hline & & 5 & & & 42.4 & 0.4108 & 275 & 8.7 \\
\hline & & 10 & & & 47.8 & 0.3941 & 306 & 20.9 \\
\hline & \multirow{3}{*}{500} & 1 & \multirow{3}{*}{0.002} & \multirow{3}{*}{4.7089} & 40.4 & 0.3663 & 354 & 0.0 \\
\hline & & 5 & & & 42.4 & 0.4108 & 401 & 13.2 \\
\hline & & 10 & & & 47.8 & 0.3941 & 439 & 24.0 \\
\hline \multirow{15}{*}{$\mathrm{SC}$} & \multirow{5}{*}{100} & 0.5 & \multirow{5}{*}{0.001} & \multirow{5}{*}{2.395044} & 22.9 & 0.3149 & 56 & -7.7 \\
\hline & & 1 & & & 24.6 & 0.2966 & 61 & 0.0 \\
\hline & & 2 & & & 26.0 & 0.2754 & 65 & 6.2 \\
\hline & & 5 & & & 28.3 & 0.2677 & 70 & 15.4 \\
\hline & & 10 & & & 31.3 & 0.2585 & 77 & 27.1 \\
\hline & & 0.5 & & & 22.9 & 0.3149 & 65 & -5.0 \\
\hline & & 1 & & & 24.6 & 0.2966 & 69 & 0.0 \\
\hline & 200 & 2 & 0.003 & 2.395044 & 26.0 & 0.2754 & 71 & 3.4 \\
\hline & & 5 & & & 28.3 & 0.2677 & 77 & 11.7 \\
\hline & & 10 & & & 31.3 & 0.2585 & 85 & 23.5 \\
\hline & & 0.5 & & & 22.9 & 0.3149 & 93 & -4.8 \\
\hline & & 1 & & & 24.6 & 0.2966 & 97 & 0.0 \\
\hline & 500 & 2 & 0.001 & 2.395044 & 26.0 & 0.2754 & 100 & 2.6 \\
\hline & & 5 & & & 28.3 & 0.2677 & 107 & 10.1 \\
\hline & & 10 & & & 31.3 & 0.2585 & 116 & 19.5 \\
\hline
\end{tabular}

$(P I=0)$. In this study, the extrapolation method was employed from $0.0001 \%$ strain to obtain $G_{\max }$ for the materials. Subsequently, the normalized shear modulus, $G / G_{\max }$, under different confining pressures and loading frequencies was obtained. Then, with respect to $G_{\max }$ and density, the shear wave velocity can be obtained. Results of $G / G_{\max }$ versus shear strain under confining pressures of 100,200 , and $500 \mathrm{kPa}$ and loading frequencies of $0.5,1,2,5$, and $10 \mathrm{~Hz}$ for $\mathrm{SM}$, SW, and SC materials are presented in Figure 4. The proposed curves by Seed and Idriss [7], EPRI [26], and
Kokusho [27] are also shown in the figure. Generally, at certain shear strain, as confining pressure increases, $G / G_{\max }-\gamma$ increases. There is a reverse trend against increasing loading frequency in all tested specimens; the value of $G / G_{\max }$, at certain strain, decreases as loading frequency increases. According to Figure 4, most of data points are located out of the pervious curves. The values of $G / G_{\max }$ for the SM material are less than the lower bound of Seed and Idriss [7]. On the other hand, $G / G_{\max }$ of the SC material is almost located in the suggested bounds of EPRI [26]. 


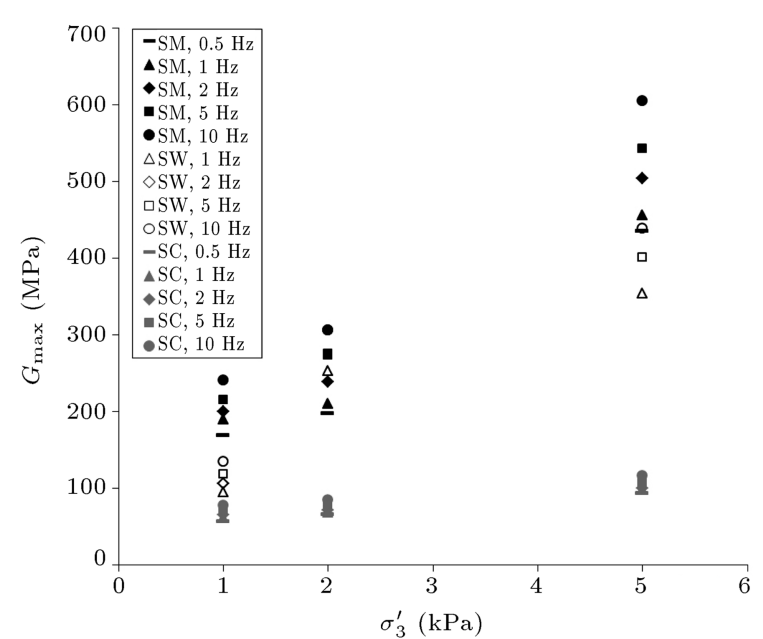

Figure 3. Variation of $G_{\max }$ versus confining pressures at loading frequencies of $0.5,1,2,5$, and $10 \mathrm{~Hz}$.

In general, SM and SC are less affected by confining pressure. The remarkable variation of $G / G_{\max }$ for $\mathrm{SW}$ material is an interesting point.

\subsection{Frequency-dependent damping ratio}

Figure 5, for instance, shows stress-strain hysteresis loop at almost the same amplitude of deviator stress for SM material under $\sigma_{3}^{\prime}=100 \mathrm{kPa}$ at the 10 th cycle and loading frequencies of 0.5 and $10 \mathrm{~Hz}$. Similar results are also obtained for SM under different confining pressures. There are some differences in the hysteresis loop; an elliptical shape may be observed at high loading frequency. The obtained hysteresis loop indicates the importance of loading frequency in damping results.

Mechanisms contributing to material damping are friction between soil particles, inertia of particles, viscosity of soil skeleton, and viscosity of pore fluid. Among them, it is perceived that the inertia acting on the individual soil particles and the system as a whole reduces the contact surface between the particles and to disturb the stable structure and orientation of grains, causing energy dissipation. In addition, dynamic loading at a higher strain rate may lead to the impact between the particles (particle collision), and the particles' decreasing tendency in volume (settlement) results in greater interaction between them, causing large energy dissipation [30-32]. Generally, the higher shear modulus obtained from resonant column and bender element tests, compared to triaxial and torsional shear tests, may be a result of higher loading frequency effect. Frequency effect on damping that was not observed in triaxial and torsional shear element tests in a previous research can be explained as follows: most of element tests are performed at very low frequencies of less than $1 \mathrm{~Hz}$. In this range, perhaps, the effect of frequency is negligible except for a creep effect, which may be observed at a very low frequency. Generally, in the resonant column test, damping was measured under free vibrations. It is not necessary for the behavior of the material to be the same under free and forced vibrations, and the material in forced vibration might not dissipate energy as expected, according to the minimum principle. Recent test results have shown a high damping ratio even at low strain levels (< $0.001 \%$ ) in non-resonant column tests $[10,14]$. All of the cyclic deviator stresses in earlier studies were applied to uniform sinusoidal cycles at frequencies of up to $0.2 \mathrm{~Hz}$ [17]. The low frequency may be selected to measure the deformation as well as machine limitations accurately.

Results of damping ratio versus shear strain at confining pressures of 100,200 , and $500 \mathrm{kPa}$ and loading frequencies of $0.5,1,2,5$, and $10 \mathrm{~Hz}$ for $\mathrm{SM}$, $\mathrm{SW}$, and SC materials are presented in Figure 6. The damping ratios of the studied soils are not significantly affected by confining pressures. However, damping ratio decreases as confining pressure increases. It is worth mentioning here that by increasing the loading frequency, damping ratio increases not only at low strain, but also at medium and high strain levels. It appears that the damping value at any loading frequency reaches a plateau value.

Generally, the damping ratio versus shear strain of the studied materials, under loading frequency of $0.5 \mathrm{~Hz}$, falls almost in the range identified previously. However, at higher loading frequencies ( 5 and 10 $\mathrm{Hz}$ ), the damping ratios completely fall above the upper bound trend observed by previous studies (see Figure 6).

Comparison of $D-\gamma$ results of the studied materials and the proposed curves by Seed and Idriss [7], Kokusho [27], and EPRI [26] for sands shows that data points of damping ratio are located almost out of upper bound proposed by Seed and Idriss [7]. Therefore, a significant difference was observed between the amounts of damping behavior of the studied materials with results available in the literature. This must be because previous studies have been performed and focused on pure sands. This could be another reason for highlighting the importance of the study on sands in decomposition of other grains, such as clay, silt, and gravels. In general, at higher shear strain levels, only insignificant amount of the data corresponding to loading frequencies of $0.5,1$, and $2 \mathrm{~Hz}$ are within the specified ranges. The maximum measured damping ratio for tested mixed sandy specimens at optimum moisture content was $40 \%$. The maximum observed damping ratio at low strains was less than $10 \%$. The reduction of damping ratio for the studied materials (less than 40\%), compared with gravelly material $(45 \%,[24])$, is possibly due to maximum grain size, fine content, grains inertia, and also moisture content conditions. As a conclusion, when implementing the proposed $D-\gamma$ curves, confining pressure, plasticity 


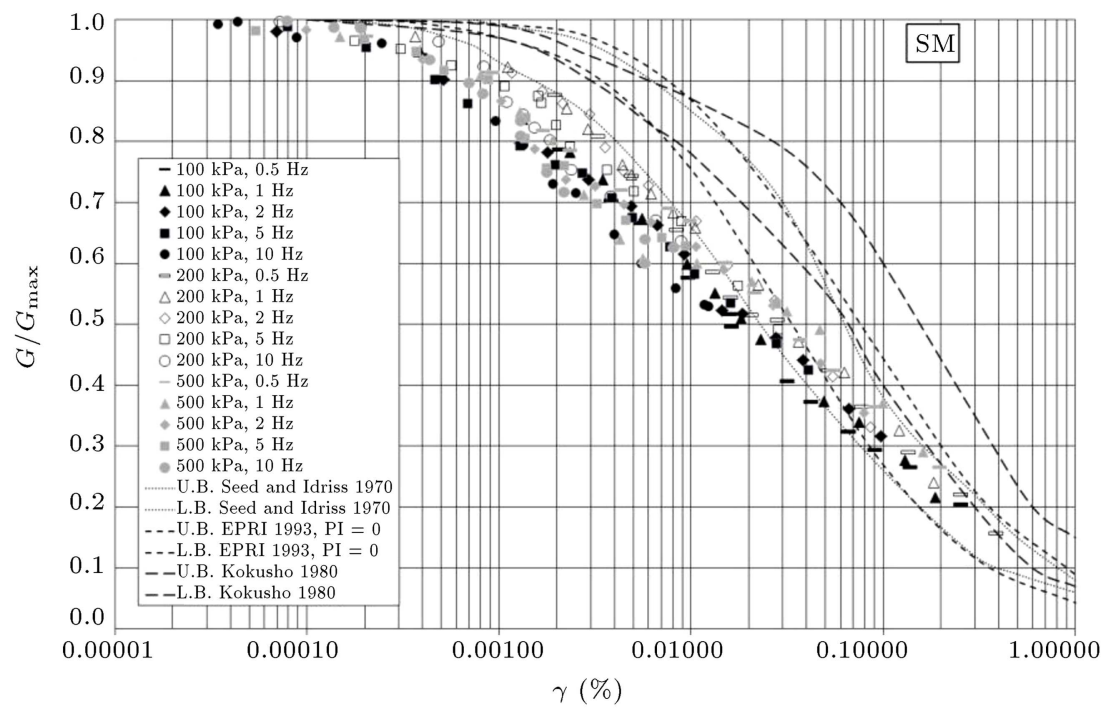

(a)

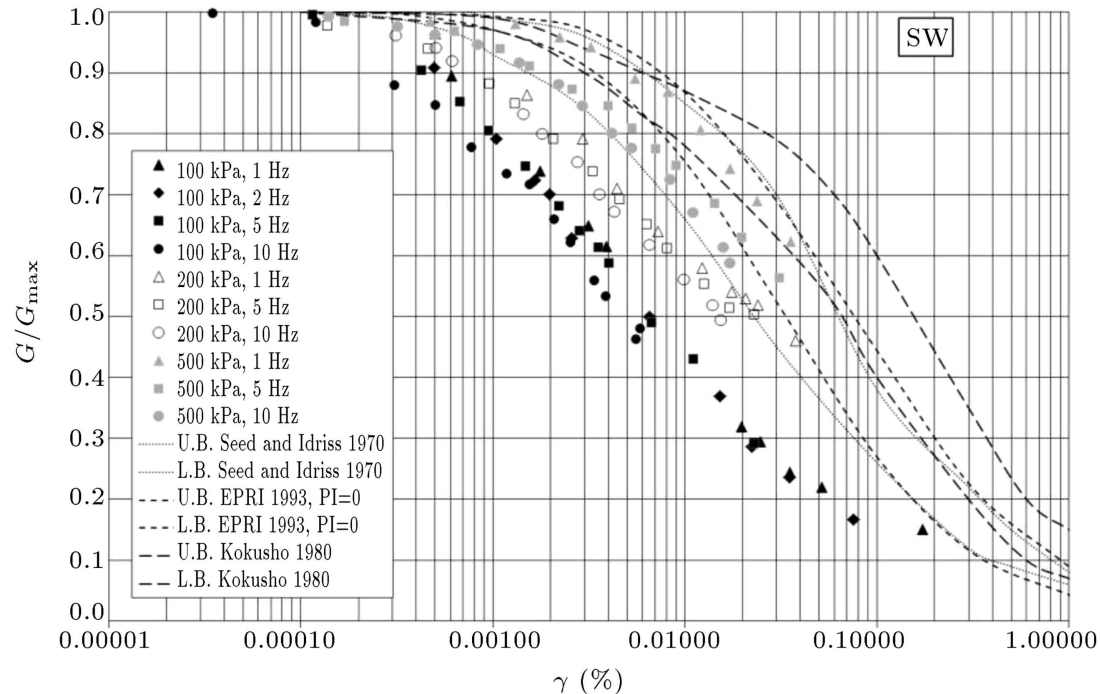

(b)

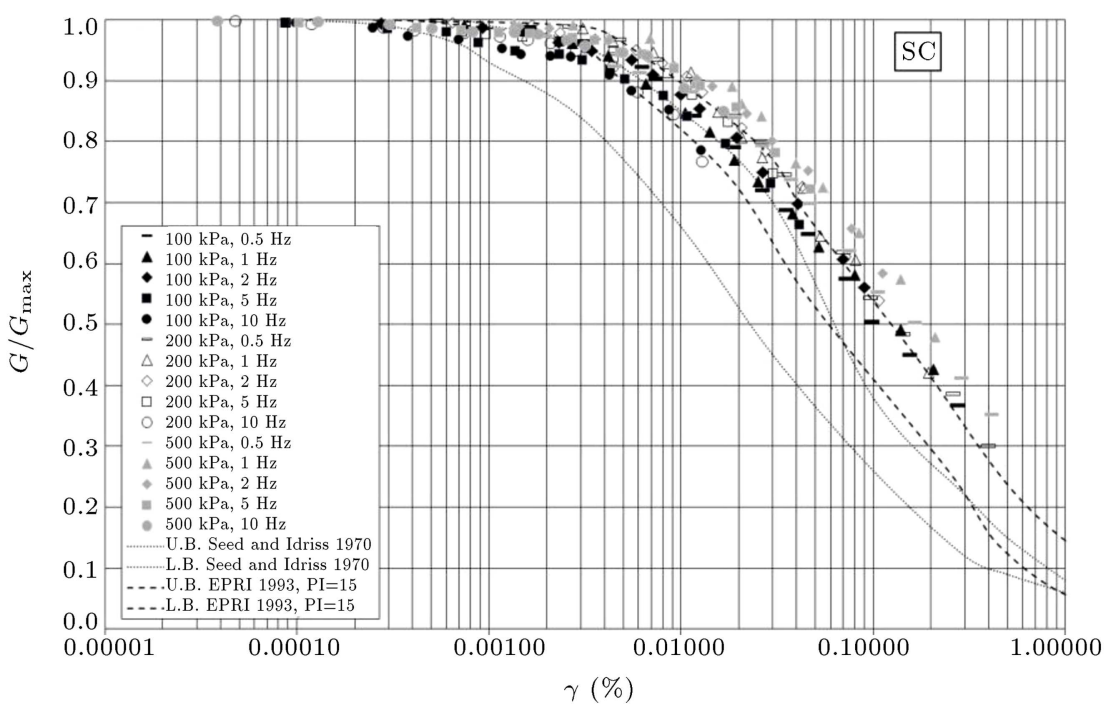

(c)

Figure 4. Results of $G / G_{\max }$ versus shear strain under different confining pressures and loading frequencies. 


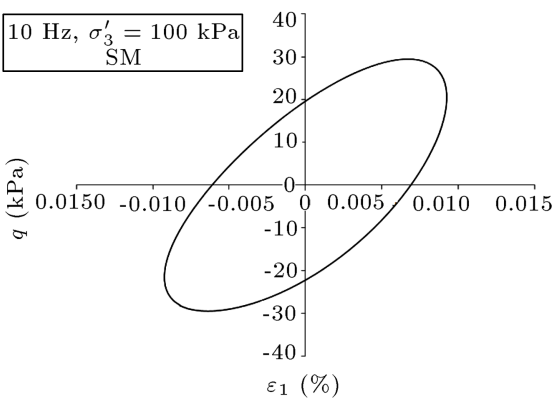

(a)

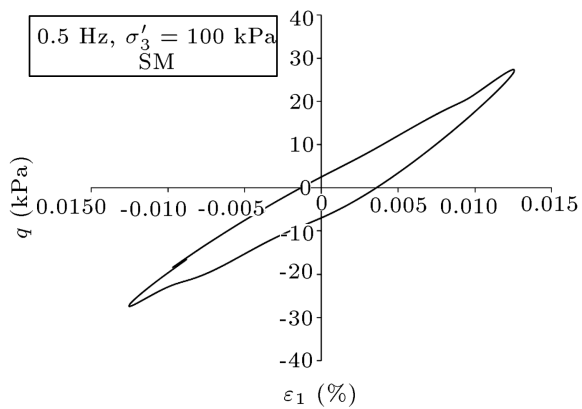

(b)

Figure 5. Stress-strain hysteresis loop for SM material at $\sigma_{3}^{\prime}=100 \mathrm{kPa}$ and the $10 \mathrm{th}$ cycle under loading frequencies of 0.5 and $10 \mathrm{~Hz}$.

index, maximum particle size, soils type, and loading frequency in particular should be considered.

\subsection{Effect of confining pressure}

The specimens of sandy materials were prepared and tested under different confining pressure conditions, as mentioned previously. According to the reviewed literature and the results of large triaxial tests, the effects of confining pressure on shear modulus are more pronounced than the other parameters. The results indicate that shear modulus (especially in SM materials) increased with an increase in confining pressure. In general, SM and SC are less affected by confining pressure. The remarkable variation of $G / G_{\max }$ for SM material is an interesting point. The damping ratios of the tested specimens are not significantly affected by confining pressures and, thus, decrease slightly as confining pressure increases.

\subsection{Effect of loading waveform}

There are different sources of vibration with different waveforms, such as traffic, machine, sea wave, and earthquake loading. There is not much research in the literature concerning the effects of frequency and waveform on the behaviors of natural sands. The effect of waveforms on $G$ and $D$ has been investigated at different confining pressures and loading frequencies. For this purpose, sinusoidal, triangular, and rectangular waveforms were applied to SM, SW, and SC specimens at the loading frequency ranging from 0.1 to $10 \mathrm{~Hz}$. The deviator stress versus time under different waveforms for SW material under confining pressure of $500 \mathrm{kPa}$ and loading frequency of $1 \mathrm{~Hz}$ is presented in Figure $7(\mathrm{a})$. The deviator stress versus axial strain is also shown in Figure 7(b). Despite the fact that the waveforms are different in appearance, they produce almost the same hysteresis loop. Therefore, in this study, shear modulus and damping ratio of the tested materials have been calculated using Eqs. (1) to (3).

The results of shear modulus and damping ratio for different waveforms are presented in Figure 8. According to Figure 8, the loading waveform has minor effect on shear modulus of the tested materials. Generally, shear modulus related to triangular waveform has greater values than sinusoidal and rectangular waveforms. Results also showed that damping ratio of triangular waveform is higher than that of the sinusoidal and rectangular waveforms. Aghaei Araei et al. [24] reported the opposite trend for gravelly materials.

\subsection{Effect of number of cycles}

The effect of the number of cycles has been taken into consideration by many researchers. The increasing number of applied cycles may affect the damping ratio and shear modulus at medium and large strain levels $[5,7]$. This subject is also considered in this study.

Figure 9, for instance, shows the test results including the effects of the number of cycles on $G$ value (i.e., $G_{10} / G_{40} ; G_{10}=\operatorname{modulus} G$ for the 10 th cycle, and $G_{40}=$ modulus $G$ for the 40 th cycle) versus shear strain for the tested specimens under sinusoidal waveform of mixed sandy materials. Generally, the values of $G_{10} / G_{40}$ increased at strain between 0.01 and $0.5 \%$. The values of $G_{10} / G_{40}$ are between 0.94 and 1.12 for strain less than $0.1 \%$. The value of $G_{10} / G_{40}$ increased slightly at shear strain higher than $0.1 \%$. Variations of $D_{10} / D_{40}\left(D_{10}=\right.$ damping $(D)$ for the 10th cycle and $D_{40}=$ damping for the 40th cycle) versus shear strain for the tested specimens under sinusoidal waveform of mixed sandy materials are also shown in Figure 9. This figure indicates that the effects of the number of cycles on damping ratio are negligible, too. However, the variations of $D_{10} / D_{40}$ range from 0.96 to 1.10 (for strain up to $0.1 \%$ ). As a result, it appears that $G_{10} / G_{40}$ and $D_{10} / D_{40}$ results were not significantly affected by the number of cycles (up to strain less than $0.1 \%$ ) for the mixed sandy materials. It must be noted that the number of cycles does not affect the general trend of $G-\gamma$ and $D-\gamma$ curves, especially at low strains [24].

\subsection{Excess pore water pressure and pore pressure ratio}

Generally, excess pore water pressure will be generated 


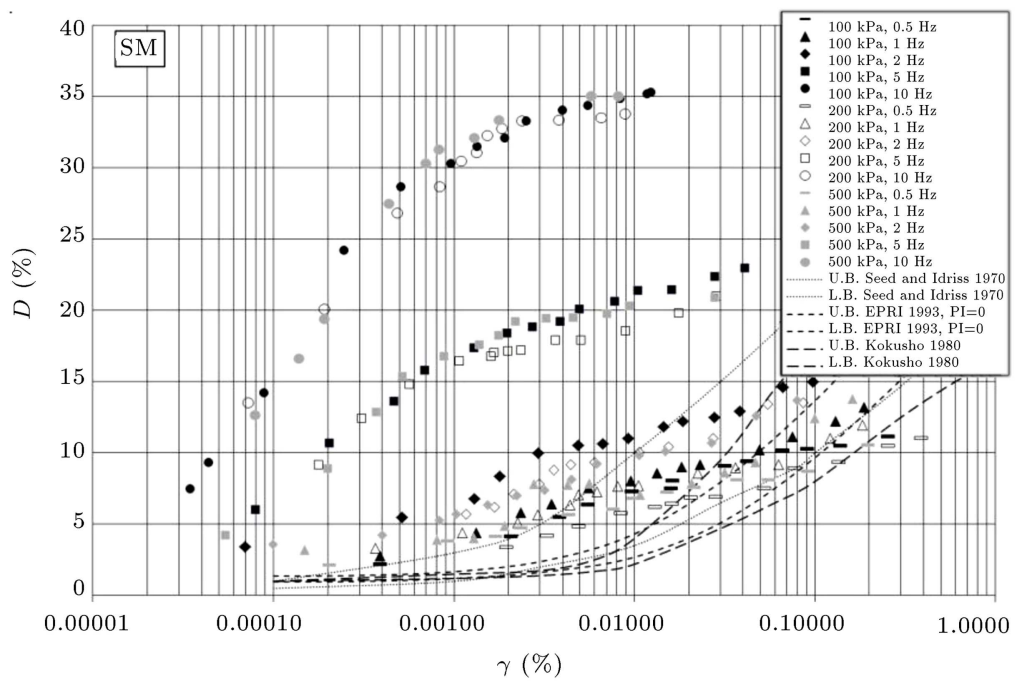

(a)

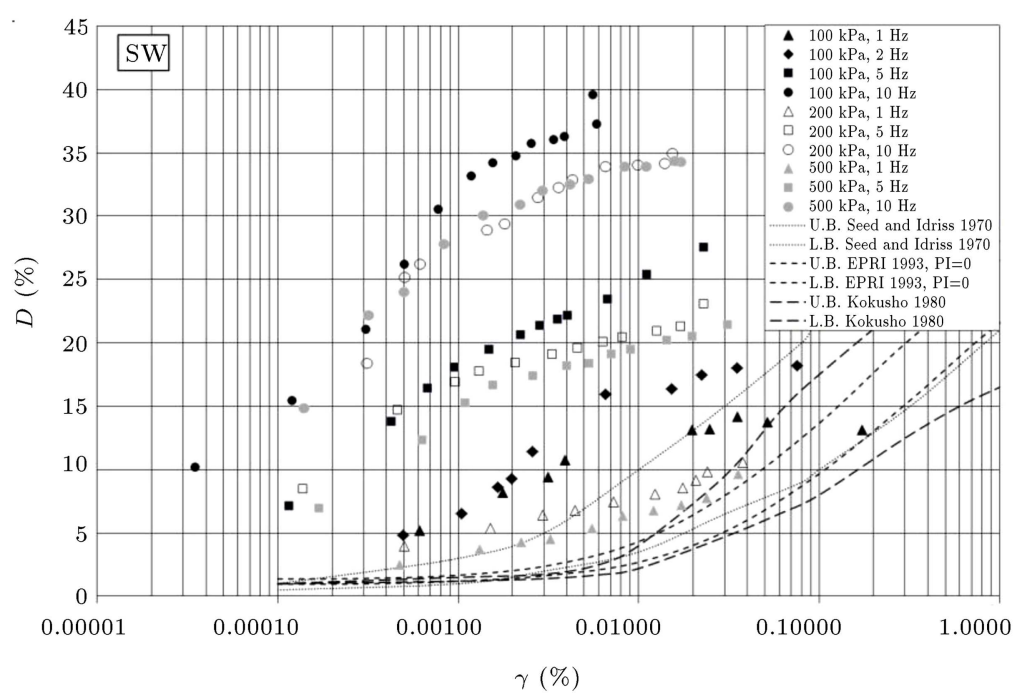

(b)

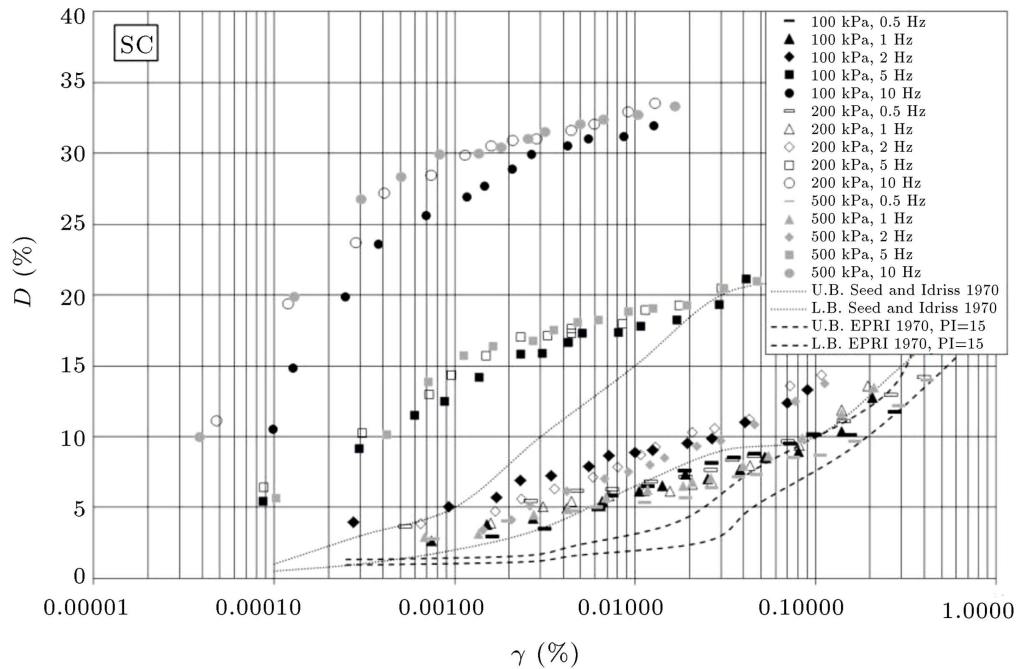

(c)

Figure 6. Results of damping ratio versus shear strain at different confining pressures and loading frequencies: (a) SM, (b) SW, and (c) SC. 


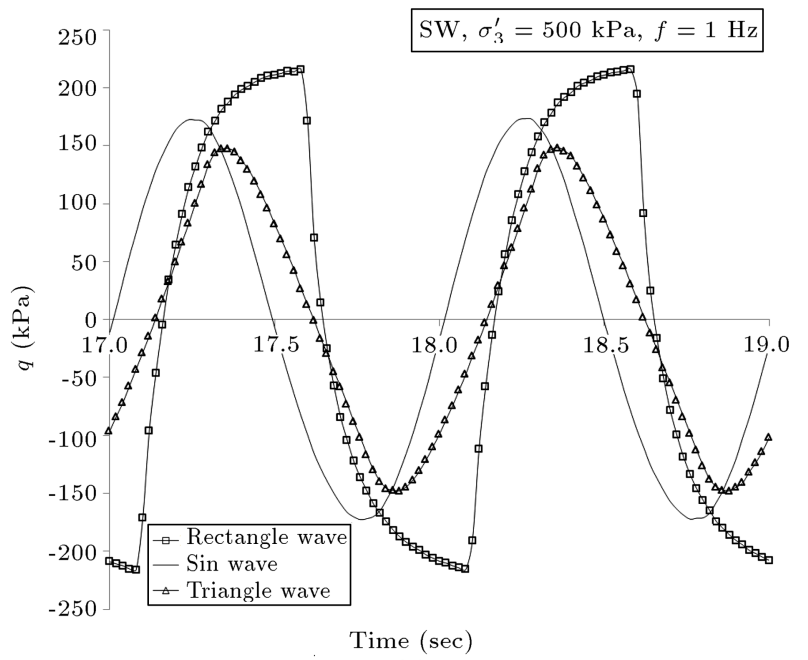

(a)

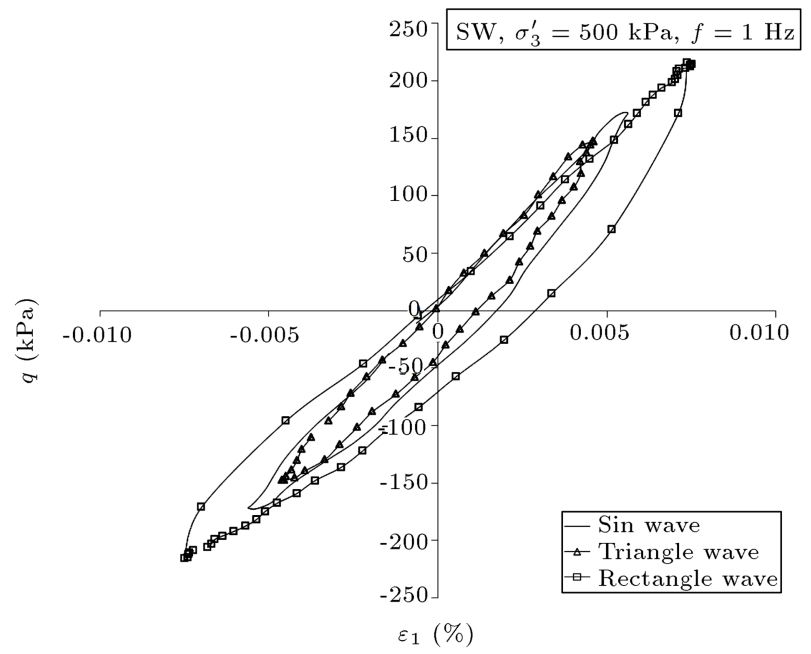

(b)

Figure 7. The effect of waveform: (a) Deviator stress versus time and (b) deviator stress versus axial strain.

during the cyclic test under different conditions. The increase in excess pore water pressure may affect the values of dynamic parameters, including shear modulus and damping ratio. For this reason, its value must be considered during the tests. Pore water pressure in the specimen has been measured directly using a very stiff electronic pressure transducer. Axial loads, vertical displacements, volume changes, and pore pressures were measured at periodic intervals of $0.04,0.02$, $0.01,0.004$, and 0.002 seconds, respectively, for the applied load with frequencies of $0.5,1,2,5$, and 10 $\mathrm{Hz}$ in undrained conditions, as mentioned previously. Figure 10, for instance, shows the generated excess pore water pressure during cyclic loading test for SM materials under confining pressure of $500 \mathrm{kPa}$ at different loading frequencies. Generally, the generated pore water pressure was negligible, especially at high frequency (e.g., 5 and $10 \mathrm{~Hz}$ ) due to the preparation of samples at their optimum moisture content, as

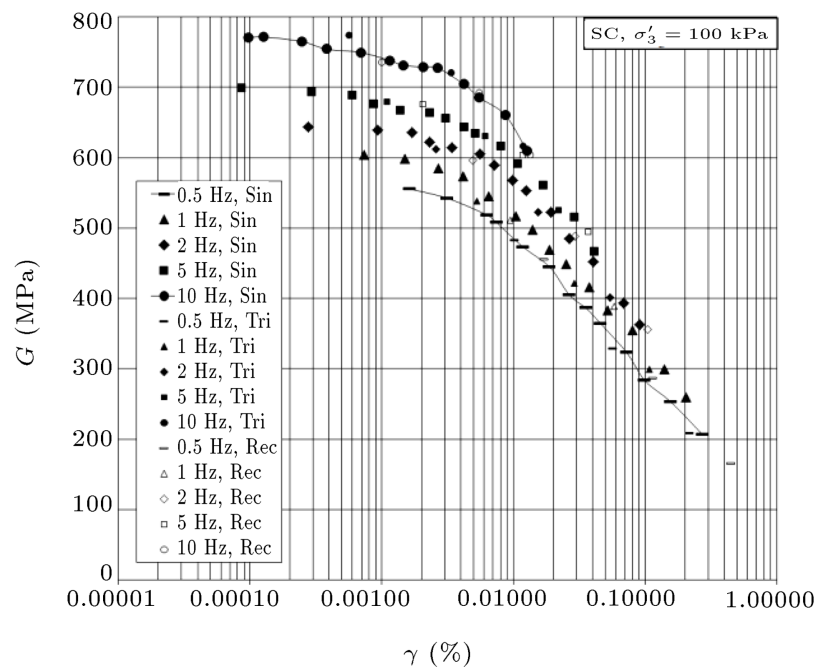

(a)

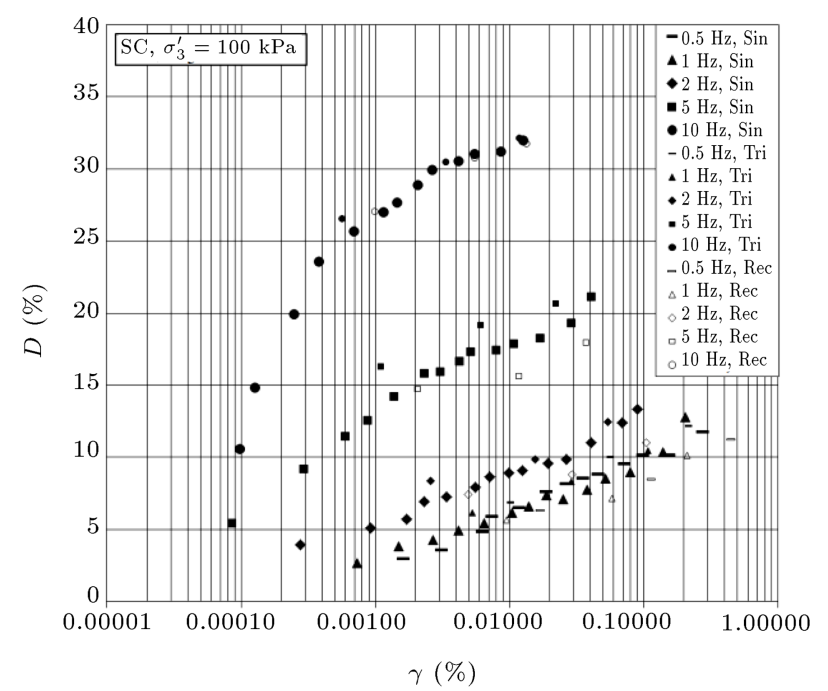

(b)

Figure 8. Results of (a) $G-\gamma$ and (b) $D-\gamma$ at confining pressures of $100 \mathrm{kPa}$ under loading frequencies of $0.5,1,2$, 5 , and $10 \mathrm{~Hz}$ and sinusoidal, triangular, and rectangular waveforms of SW specimen.

expected (see Figure 10). An increase in the loading frequency leads to the increase of the generated EPWP during cyclic loading triaxial tests at high strain levels $(\gamma>0.1 \%)$. However, the maximum observed EPWP was less than $8 \mathrm{kPa}$ (at higher stress amplitude for low frequency loading, e.g., $0.5 \mathrm{~Hz}$ ) and could not influence shear modulus and damping ratio results. The variations of excess pore water pressure at the 40th cycle versus shear strain of the studied mixed sandy materials are also shown in Figure 11. The variations are presented for tests under different confining pressures and loading frequencies. It appears that the pore water pressure is not affected by the loading frequency and is only proportional to the strain level. The effect of strain level increased as confining pressure increased. The maximum measured generated excess pore water 


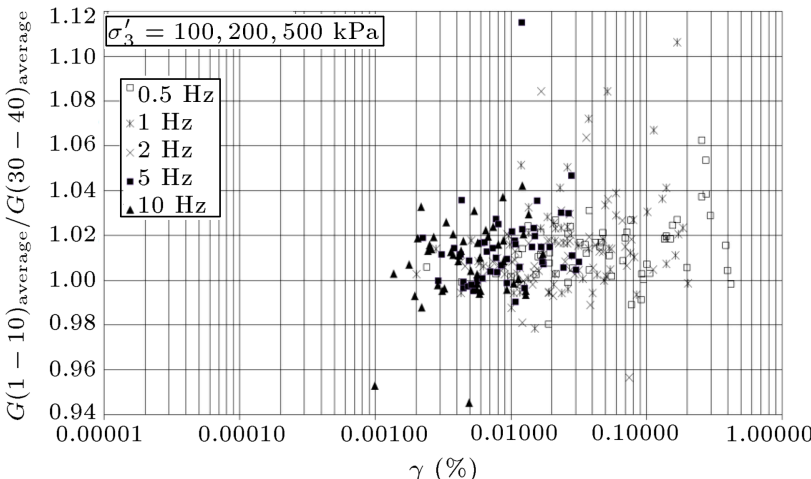

(a)

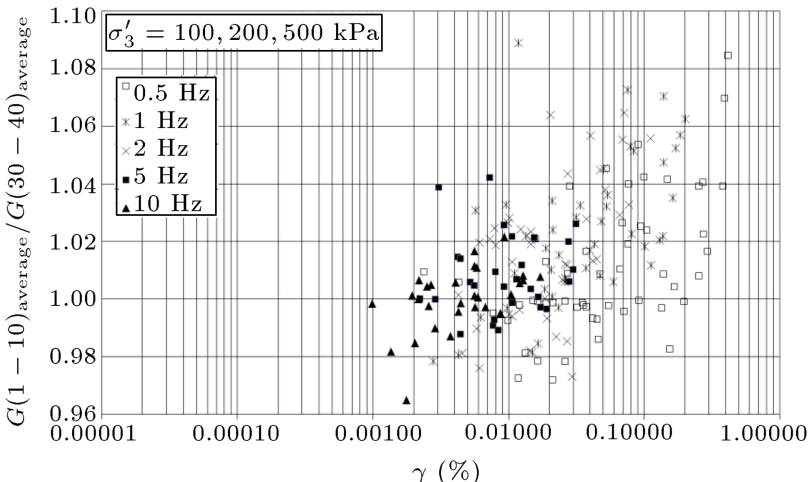

(b)

Figure 9. Effect of the number of cycles on (a) $G_{10} / G_{40}$ and (b) $D_{10} / D_{40}$ results versus shear strains of the mixed sandy specimens under sin wave.

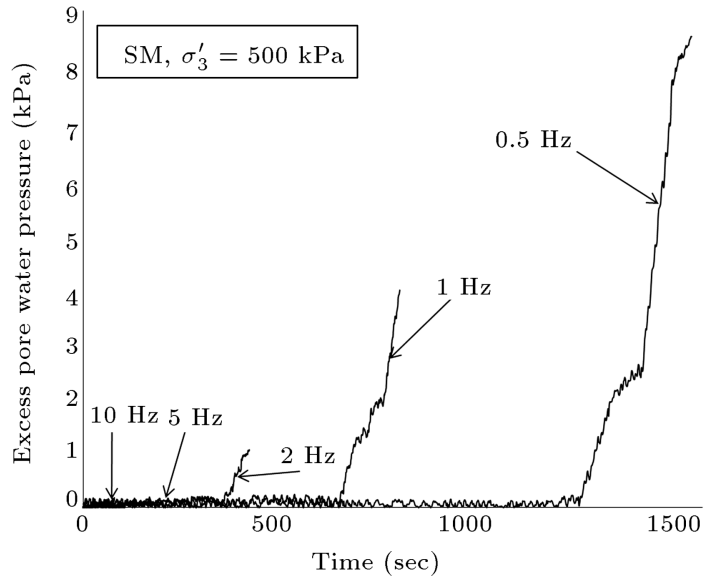

Figure 10. The time history of the generated excess pore water pressure through cyclic loading for SM materials under confining pressure of $500 \mathrm{kPa}$ at different loading frequencies.

pressure in cyclic tests was negligible and less than 9 $\mathrm{kPa}$. The variations of pore pressure ratio $\left(U_{\max } / \sigma_{3}^{\prime}\right)$ at different levels of shear strain for the 40th cycle are also shown in Figure 12. According to Figure 12, the amount of pore pressure ratios was less than 7 percent in all studied strain levels.

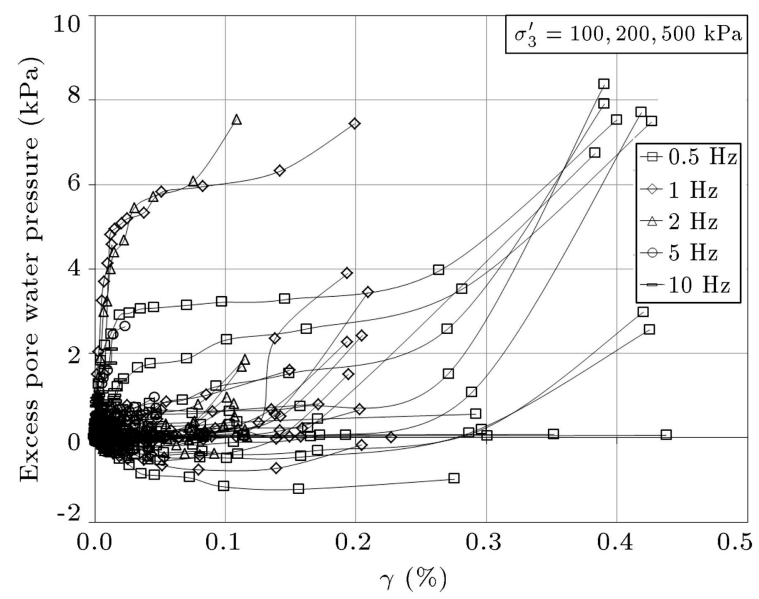

Figure 11. Variations of excess pore water pressure at the 40th cycle versus shear strain of the mixed sandy materials.

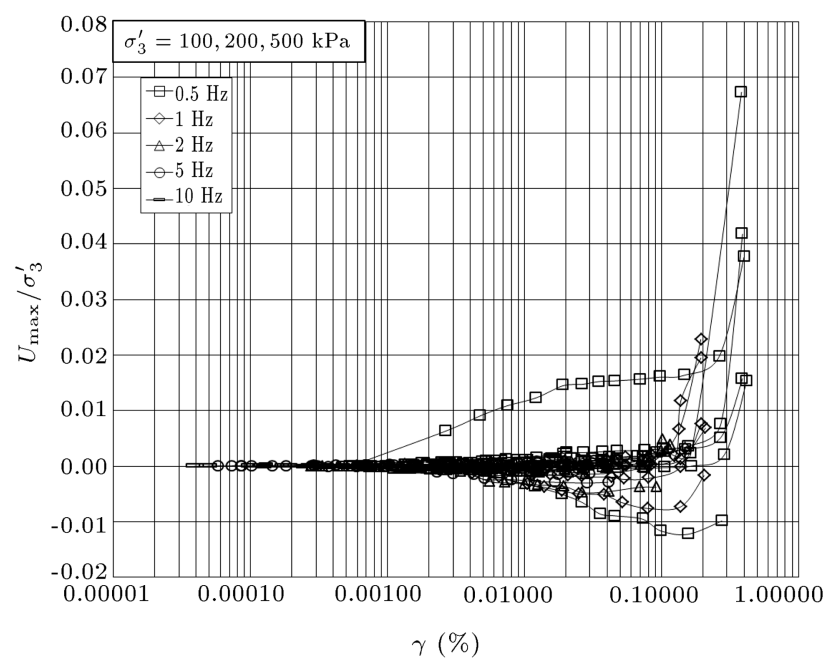

Figure 12. Variations of pore pressure ratio at different levels of shear strain under different confining pressures and loading frequencies at the 40th cycle.

\subsection{Volume change and axial displacement}

The volume change often has been reduced by opening drainage valve in triaxial tests. Thus, the sample will be denser slightly. As mentioned before, any volume change depends on axial strain level, saturation degree, number of applied cycles, and soil type. The change in density is negligible for the small strain. It was still very small even for strain amplitudes of up to $0.1 \%$ if the number of strain cycles was limited [5]. The variations of volume change versus shear strain at the end of each loading step under different confining pressures and loading frequencies for tested materials are shown in Figure 13. According to Figure 13, water flows in or out of the cylindrical sample by opening the drainage valve depending on the confining pressure and saturation degree. The reduction in the volume of the released water by an increase in confining pressure 


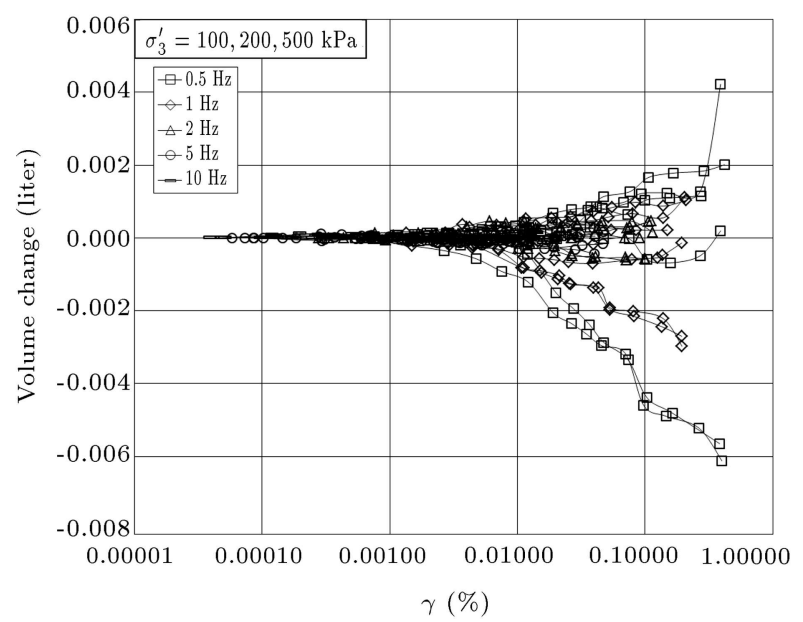

Figure 13. Variations of volume change versus shear strain under different confining pressures and loading frequencies at the 40 th cycle.

is an interesting point. Moreover, the highest degree of variation in the volume change occurred at low frequencies $(0.5$ and $1 \mathrm{~Hz})$. Test results of the mixed sandy materials indicate that the maximum observed volume change due to drainage of the specimen is 0.006 Liter and has value of 0.004 Liter at axial strain $0.1 \%$. The total volume of a cylindrical specimen with a diameter of 20 and $40 \mathrm{~cm}$ in height is 12.566 Liter. The maximum volume change observed in specimens $e$, is less than 0.05 percent of their total value. Therefore, the change in the void ratio of specimens $e$, is less than 0.05 percent, and variation of $f(e)$ will be even less. Therefore, variations in $f(e)$ have been ignored for the shear strain above $0.1 \%$ for these high compacted specimens. Moreover, the maximum observed strains in specimens were negligible (except for specimen under loading frequency of $0.5 \mathrm{~Hz}$ at shear strain greater than $0.1 \%$ ) due to the high density of the tested samples. Volume change in percent at shear strain of $0.1 \%$ is less than $0.3 \%$. Moreover, the change in density due to drainage is less than $1 \%$ at shear strain of $0.1 \%$. According to ASTM D3999 [18] and ASTM D4015 [32], a soil material typically behaves like an elastic solid exhibiting a nondestructive response to the application of cyclic loading below a threshold axial strain level of $<0.01 \%$, and many measurements of the same specimen may be made with various states of ambient stress. Therefore, it is believed that the re-use of samples for higher strain amplitudes (i.e., up to $0.1 \%$ ) still gives reasonably good results if the number of strain cycles applied is limited.

Figure 14 shows the variations of permanent axial displacement versus shear strain under different confining pressures and loading frequencies at the 40th cycle. Generally, the observed permanent axial strains at higher loading frequencies (e.g., 5 and $10 \mathrm{~Hz}$ ) are smaller than lower frequencies (e.g., $0.5 \mathrm{~Hz}$ ). According

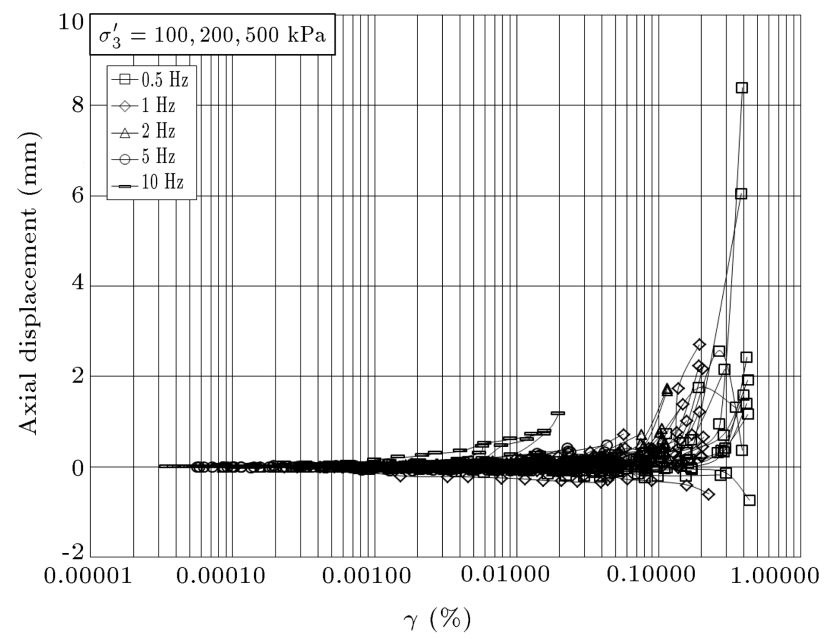

Figure 14. Variations of permanent axial displacement versus shear strain under different confining pressures and loading frequencies at the 40th cycle.

to Figure 14, the axial permanent displacements at the last stage of cyclic loading under frequency of $5.0 \mathrm{~Hz}$ are greater than $2 \mathrm{~mm}$, which rarely reach $1 \mathrm{~mm}$ for shear strains less than $0.01 \%$. Therefore, the tests may be made on the same specimen for shear strains up to $0.01 \%[18,24]$. According to the tests results, for compacted specimens, the overall trend of the shear modulus and damping ratio curves was not affected by the number of cycles and their corresponding axial permanent strains [24]. It is worth noting that the permanent axial deformation decreases as confining pressure increases.

\subsection{Comparison of $D-G / G_{\max }$ results with previous studies}

It is observed that when the results are presented in $D-G / G_{\max }$ the form, the complex effects of confining pressure are eliminated, thus facilitating the interpretation of loading frequency effect. The relationship between damping ratio and $G / G_{\max }$ is proposed by a number of researchers as follows [19]:

$$
D=A\left(G / G_{\max }\right)^{2}+B\left(G / G_{\max }\right)+C+D_{\max },
$$

where coefficients $A, B$, and $C$ are determined through test results. Results of damping ratio versus $G / G_{\max }$ under different confining pressures and loading frequencies for the sandy materials are shown in Figure 15. The proposed curves by Seed and Idriss [7], EPRI [26], and Kokusho [27] for sands are also shown. In the study of Kokusho [27], tests were carried out on nonplastic sands $(P I=0)$. Since $\mathrm{SC}$ has $15 \%$ plasticity index, the results are compared only to those of Seed and Idriss [7] and EPRI [26]. According to Figure 15 , there is good agreement between cyclic test results at loading frequency less than $1 \mathrm{~Hz}$ and the proposed curves. However, the differences are remarkable at the frequency of $2 \mathrm{~Hz}$ and, especially for $5 \mathrm{~Hz}$ and $10 \mathrm{~Hz}$. 


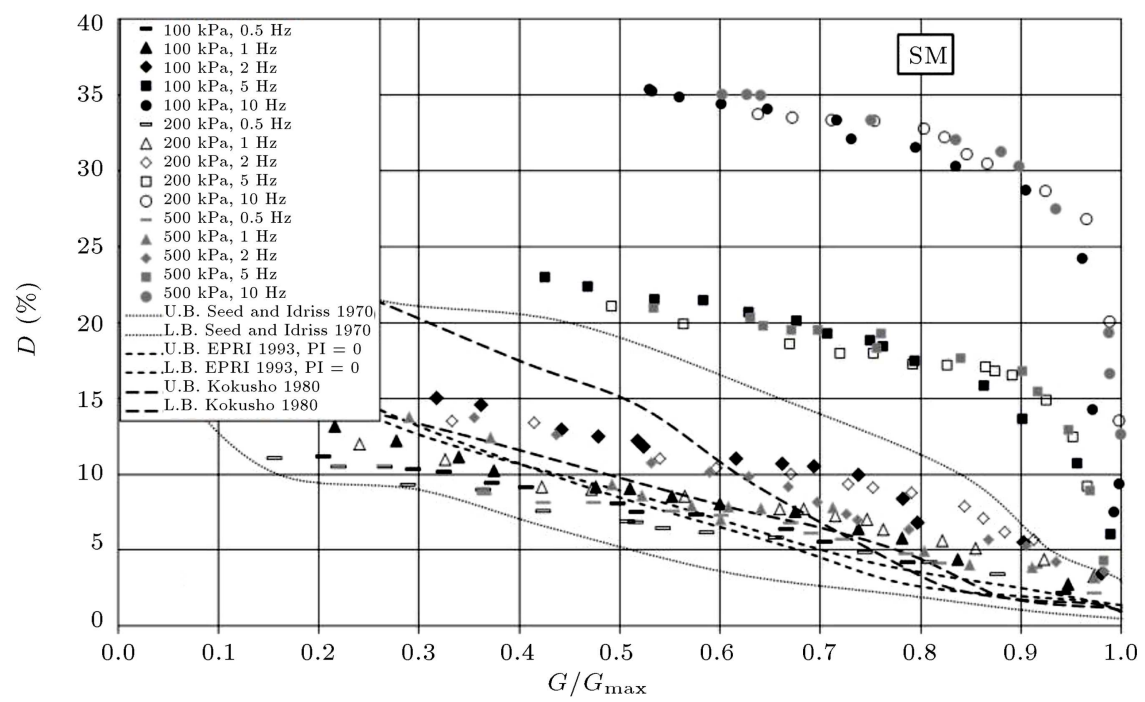

(a)

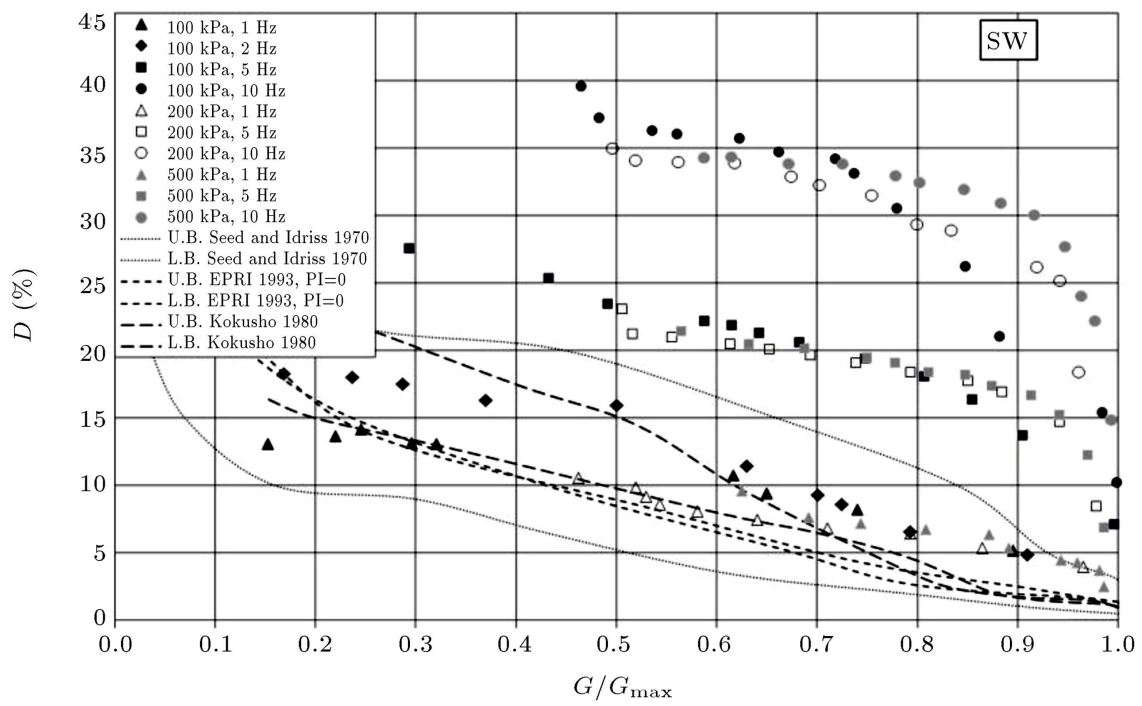

(b)

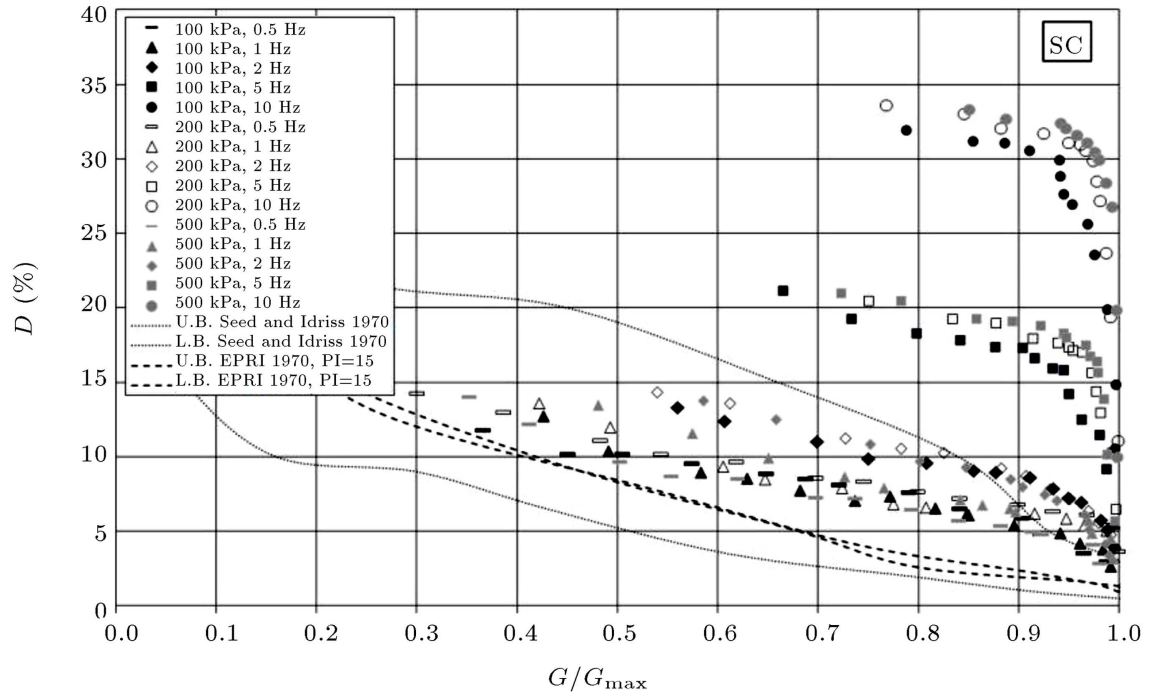

(c)

Figure 15. Results of damping ratio versus $G / G_{\max }$ under different confining pressures and loading frequencies: (a) SM, (b) SW, and (c) SC (the previous proposed upper and lower bounds for sands are also presented for comparison). 


\section{Conclusions}

In this paper, the dynamic properties (including shear modulus and damping ratio) of mixed sandy soils were evaluated. This study focused on the effects of loading frequency and confining pressure on $G$ and $D$ versus shear strain (which ranges from 0.0001 to $0.1 \%$ ). A total number of 40 triaxial tests were conducted on the large-scale cylindrical specimens with a diameter of 200 and $400 \mathrm{~mm}$ in height. The main findings of this study may be summarized as follows:

- The increase in loading frequency causes an increase in shear modulus at low strain. However, the rate of the increase in $G$ due to the increase of loading frequency may decrease as the strain increases;

- Generally, for SW material, as confining pressure increases, $G / G_{\max }-\gamma$ curve moves from the lower bound toward the upper bound proposed by previous researchers. There are reverse trends against the increasing loading frequency in all tested specimens; $G / G_{\max }-\gamma$ curve moves from the upper bound toward the lower bound. Generally, at certain strain, $G / G_{\max }-\gamma$ decreases as loading frequency increases. However, SM and SC materials are less affected by confining pressure;

- The damping ratios of the studied soils are not significantly affected by confining pressures. However, damping ratio decreases as confining pressures increase, especially at high confining pressures $(500 \mathrm{kPa})$. It is worth noticing here that, with the increasing loading frequency, damping ratio increases not only at low strain, but also at medium and high strain levels. It appears that the damping value at any loading frequency at higher strains level would reach a plateau value;

- Comparison of $D-\gamma$ results of the studied materials and the proposed curves by Seed and Idriss [7], Kokusho [27], and EPRI [26] shows that the data points of damping ratio are located almost out of upper bound, as proposed by Seed and Idriss [7]. The differences are remarkable at the frequencies of 5 and $10 \mathrm{~Hz}$;

- A significant difference is observed between the amounts of damping behavior of the studied materials with results available in the literature. This must be due to the fact that previous studies have been specifically carried out and focused on pure sands. This could be another reason for highlighting the importance of the study on sands in decomposition of other grains, such as clay, silt, and gravels. When implementing the proposed $D_{y}$ curves, confining pressure, plasticity index, maximum particle size, soils type, and loading frequency in particular should be considered;
- The effect of triangular, sinusoidal, and rectangular waveforms on the dynamic behavior is negligible. However, shear modulus and damping ratio of triangular waveform are slightly higher than those of sinusoidal and rectangular waveforms are;

- Effects of the number of cyclic loading and excess pore water pressure on $G / G_{\max }$ and $D$ are negligible at strains smaller than $0.01 \%$. The volume change and permanent axial displacement are also negligible and decrease as confining pressure increases.

Finally, considering the effects of loading frequency on shear modulus and, especially, damping behavior, tests should be programmed in a proper manner in terms of loading frequency and number of cyclic loading. The results of this study may be applicable to consultants, contractors, employers, and practitioners in seismic microzonation projects for similar materials.

\section{Acknowledgments}

This work was carried out during the research work conducted by the second author for a doctoral degree at the Road, Housing and Urban Development Research Center (BHRC). The research was supported by BHRC under grants 39-9907(2011) and 39-4773(2013). The authors are thankful for the technical help and assistance provided by the Department of Geotechnical Engineering of BHRC.

\section{Nomenclature}

$\begin{array}{ll}G & \text { Shear modulus } \\ D & \text { Damping ratio } \\ \gamma & \text { Shear strain } \\ \mathrm{Hz} & \text { Hertz } \\ \mathrm{kPa} & \text { Kilo Pascal } \\ D_{\text {min }} & \text { Minimum value of damping ratio } \\ G_{s} & \text { Specific gravity } \\ D_{(10)},(\mathrm{mm}) & \begin{array}{l}\text { Particle size }(\mathrm{mm}) \text { corresponding to } 10 \\ \text { passing percentage, respectively }\end{array} \\ D_{(30)},(\mathrm{mm}) & \begin{array}{l}\text { Particle size (mm) corresponding } 30, \\ \text { passing percentage, respectively }\end{array} \\ D_{(50)},(\mathrm{mm}) & \begin{array}{l}\text { Particle size (mm) corresponding to } 50 \\ \text { passing percentage, respectively }\end{array} \\ e_{0} & \text { Void ratio according to modified } \\ & \text { proctor compaction } \\ \gamma_{d} & \text { Dry density } \\ \omega_{\text {opt }} & \text { Optimum water content } \\ \mathrm{PI} & \text { Plasticity Index } \\ \sigma_{3}^{\prime} & \text { Effective minor principal stress, } \\ & \text { Effective confining pressure } \\ & \end{array}$




$\begin{array}{ll}\text { MPa } & \text { Mega Pascal } \\ E & \text { Young modulus } \\ \tau & \text { Shear stress } \\ v & \text { Poisson's ratio } \\ \varepsilon_{1} & \text { Axial strain } \\ V_{p} & P \text { wave velocity } \\ V_{s} & S \text { wave velocity } \\ G_{\max } & \text { Maximum value of shear modulus } \\ \text { L.B. } & \text { Lower Bound } \\ \text { U.B. } & \text { Upper Bound }\end{array}$

\section{References}

1. Lade, P.V. and Yamamuro, J.A. "Effects of nonplastic fines on static liquefaction of sands", Can. Geotech. J., 34(6), pp. 918-928 (1997).

2. Thevanayagam, S. and Mohan, S. "Intergranular state variables and stress-strain behaviour of silty sands", Géotechnique, 50(1), pp. 1-23 (2000).

3. Janalizadeh, A., Ghalandarzadeh, A., and Esmaeili, M. "Behavior of sand- gravel composite with two different method under seismic liquefaction conditions", Technical Journal of Engineering and Applied Silences, 2(6), pp. 123-131 (2012).

4. Kong, X., Xu, B., and Zou, D. "experimental study on the behaviors of sand-gravel composites liquefaction", Soil Stress-Strain Behavior: Measurement and Analysis, Geotechnical Symposium in Roma, March 16 \& 17 (2006).

5. Seed, H.B., Wong, R.T., Idriss, I.M., and Tokimatsu, K. "Moduli and damping factors for dynamic analyses of cohesionless soils", J. Geotech. Eng., 112(11), pp. 1016-1032 (1986).

6. Aghaei Araei, A., Razeghi, H.R., Ghalandarzadeh, A., and Hashemi Tabatabaei, S. "Effects of loading rate and initial stress on stress-strain behavior of rock fill materials under monotonic and cyclic loading conditions", J. Scientia Iranica, 19(5), pp. 1220-1235 (2012).

7. Seed, H.B. and Idriss, I.M. "Soil moduli and damping factors for dynamic analysis", Report No. EERC 7010, University of California, Berkeley (1970).

8. Idriss, I.M. "Response of soft soil sites during earthquakes", Proc. H. Bolton Seed Memorial Symposium, J.M. Duncan (editor), 2, pp. 273-290 (1990).

9. Park, D. and Hashash, Y.M.A. "Rate-dependent soil behavior in seismic site response analysis", Canadian Geotechnical Journal, 45(4), pp. 454-469 (2008).

10. Lai, C.G., Pallara, O., Lo Presti, D.C., and Turco, E. "Low-strain stiffness and material damping ratio coupling in soils, Advanced laboratory stress-strain testing of geomaterials", T. Tatsuoka, S. Shibuya, and R. Kuwano, Eds., Balkema, Lisse, The Netherlands, pp. 265-274 (2001).
11. Meng, J. "Earthquake ground motion simulation with frequency-dependent soil properties", Soil Dynamics and Earthquake Engineering, Elsevier, 27, pp. 234-241 (2007).

12. Meza-Fajardo, K.C. and Lai, C.G. "Explicit causal relations between material damping ratio and phase velocity from exact solutions of the dispersion equations of linear viscoelasticity", Geophysical Journal International, 171(3), pp. 1247-1257 (2007).

13. Rix, G.J. and Meng, J. "A non-resonance method for measuring dynamic soil properties", Geotech. Test. J., 28(1), pp. 1-8 (2005).

14. Khan, Z.H., Cascante, G., El Naggar, M.H., and Lai, C.G. "Measurement of frequency-dependent dynamic properties of soils using the resonant-column device", Journal of Geotechnical and Geoenvironmental Engineering, ASCE, 134(9), pp. 1319-1326 (2008).

15. Shibuya, S., Mitachi, T., Fukuda, F., and Degoshi, T. "Strain-rate effects on shear modulus and damping of normally consolidated clay", Geotech. Test. J., 18(3), pp. 365-375 (1995).

16. Feizi-Khankandi, S., Mirghasemi, A.A., Ghalandarzadeh, A., and Hoeg, K. "The cyclic triaxial tests on asphalt concrete as a water barrier for embankment dams", Soils and Foundations, 48(3), pp. 319-332 (2008).

17. Rollins, K.M., Evans, M.D., Diehl, N.B., and Daily, W.D. "Shear modulus and damping relationships for gravels", Journal of Geotechnical and Geoenvironmental Engineering, ASCE, 124(5), pp. 398-405 (1998).

18. ASTM D3999. "Standard test methods for the determination of the modulus and damping properties of soils using the cyclic triaxial apparatus", Annual Book of ASTM Standard, ASTM International, West Conshohocken, PA (2006).

19. Zhang, J., Andrus, R., and Juang, C.H. "Normalized shear modulus and material damping ratio relationships", Journal of Geotechnical and Geoenvironmental Engineering, ASEC, 130(4), pp. 453-464 (2005).

20. Aghaei Araei, A., Tabatabaei, S.H., and Ghalandarzadeh, A. "Assessment of shear modulus and damping ratio of gravelly soils", Research Project, No. 34469-2007, BHRC, Iran (2008).

21. Maheshwari, B.K., Kale, S.S., and Kaynia, A.M. "Dynamic properties of Solani sand at large strains: a parametric study", International Journal of Geotechnical Engineering, 6, pp. 353-358 (2012).

22. Aghaei Araei, A., Tabatabaei, S.H., and Ghalandarzadeh, A. "Assessment of shear modulus and damping ratio of gravelly soils", BHRC Publication, No. R548, BHRC, Iran (2011a).

23. Aghaei Araei, A., Razeghi, H.R., Tabatabaei, S.H., and Ghalandarzadeh, A. "Evaluation of frequency content on properties of gravelly soils", BHRC Publication, No. R-630, BHRC, Iran (2011b). 
24. Aghaei Araei, A., Razeghi, H.R., Tabatabaei, S.H., and Ghalandarzadeh, A. "Loading frequency effect on stiffness, damping and cyclic strength of modeled rockfill materials", Soil Dynamics and Earthquake Engineering, Elsevier, 33(1), pp. 1-18 (2012).

25. Ling, X.Z., Zhang, F., Li, Q.L., and Wang, J.H. "Dynamic shear modulus and damping ratio of frozen compacted sand subjected to freeze-thaw cycle under multi-stage cyclic loading", Soil Dynamics and Earthquake Engineering, 76, pp. 111-121 (2015).

26. Electric Power Research Institute (EPRI), "Guidelines for determining design basis ground motions", Final Rep. No. TR-102293, Palo Alto, Calif (1993).

27. Kokusho, T. "Cyclic triaxial test of dynamic soil properties for wide strain range", Soils and Foundations, 20, pp. 45-60 (1980).

28. ASTM D698 "Standard test methods for laboratory compaction characteristics of soils using standard effort" (2007).

29. Nishio, N., Tamaoki, K., and Machida, Y. "Dynamic deformation characteristics of crushed gravel by means of large-size triaxial test apparatus", Proceedings of the 2th Annual Convention, Japanese Society of Soil Mechanics and Foundation Engineering, pp. 603-604 (1985).

30. Sundarraj, K.P. "Evaluation of deformation characteristics of 1-G model ground during shaking using a laminar box", PhD Dissertation, University of Tokyo, Japan (1996).
31. Kallioglou, P., Tika, T.H., and Pitilakis, K. "Shear modulus and 938 damping ratio of cohesive soils", $J$. Earthquake Eng. 12(6), pp. 879-913 (2008).

32. ASTM D4015. "Standard test methods for modulus and damping of soils by the resonant-column method", Re-approved 2000 (1992).

\section{Biographies}

Ata Aghaei Araei received his $\mathrm{PhD}$ degree from Iran University of Science and Technology (IUST), Iran in 2011. He also was a PhD Researcher at the Geotechnical Laboratory of Civil Engineering at The University of Tokyo. Since 2003, he has been working as a Senior Geotechnical Engineer and the Head of the Geotechnical Laboratory at the Building and Housing Research Center (BHRC). Dr. Aghaei Araei's primary research interests include monotonic and dynamic testing on geomaterials, microzonation, and geotechnical equipment construction.

Ahmadreza Ghodrati received his MD degree from Arak University, Iran in 2012 and is now a PhD student at the Institute of Building and Housing, Road, Housing and Urban Development Research Center (BHRC) in Iran. His primary research interests include risk assessment, geotechnical and geoenvironmental engineering, and dynamic testing on geomaterials. 